\title{
Neuronal Activities Underlying the Electroencephalogram and Evoked Potentials of Sleeping and Waking: Implications for Information Processing
}

\author{
ANTON M. L. COENEN \\ NICI, Department of Psychology, University of Nijmegen, P.O. Box 9104, $6500 \mathrm{HE}$ Nijmegen, \\ The Netherlands, E-Mail: COENEN@NICI.KUN.NL
}

Received 31 March 1994

\begin{abstract}
COENEN, A. M. L. Neuronal activities underlying the electroencephalogram and evoked potentials of sleeping and waking: Implications for information processing. NEUROSCI BIOBEHAV REV 19(3) 447-463, 1995. - The low amplitude, high frequency waves of the electroencephalogram (EEG) indicative of wakefulness, are produced by a summation of potentials of thalamocortical neurons, which fire in a "tonic mode" of depolarization. In this mode, the transfer of information from the peripheral sense organs to the sensory cortex is facilitated, due to a tonic lowering of the discharge threshold of thalamocortical neurons. The transfer decreases during drowsiness when thalamocortical units are more hyperpolarized and have higher thresholds. In this state, neurons fire synchronously in a "burst mode," which is expressed in EEG spindling. During slow wave sleep sensory blocking reaches a maximum, when thalamocortical cells are yet more deeply hyperpolarized, although that what still passes to the cortex allows a shallow, subconscious, evaluation. The collective burst firing is more irregular, which results in large and slow EEG waves. In contrast, during rapid eye movement (REM) sleep the depolarized tonic mode of firing commonly associated with waking, is again reached. Similar to EEG-patterns, the architecture of evoked potentials is dependent on the state of alertness. During waking, components in event related potentials (ERP) are moderate in amplitude, while during slow wave sleep larger waves are visible. This is caused by more synchronized unit responses with sharper phases of excitations and inhibitions, which results from increased hyperpolarizations. In contrast, visual ERPs belonging to REM sleep closely resemble those of wakefulness. In analyzing unit responses of thalamocortical neurons, it appeared that neuronal excitations are expressed in negative components of the ERP, while inhibitory neuronal activities are associated with positivity. Transient phenomena in the EEG, such as ERP waves, spindles and spike-wave discharges, are the expression of synaptic potentials in superficial cortical layers, where numerous synapses of afferent thalamocortical fibers are localized on the apical dendrites of deeper lying pyramidal neurons. It is suggested that the morphology of these EEG components is primarily due to the discharge characteristics of thalamocortical relay cells, whereby excitations underly negative waves and inhibitions positive waves. The notion of a general correspondence between thalamocortical neuronal activities and the polarity of transients in the cortical surface EEG, allows prudent speculations regarding components of ERPs. Two examples are given: the contingent negative variation (CNV) and the P300 of an ERP which can be elicited by an infrequent stimulus. The EEG negativity in the CNV, regarded as a readiness potential, is interpreted as the expression of a general neuronal activation, while the positivity of the second EEG phenomenon may be considered as associated with inhibitory processes related to specific processes of stimulus recognition.
\end{abstract}

Electroencephalogram Neuronal activity Sleeping and waking Transfer ratio Event related potentials Information processing

\section{INTRODUCTION}

MORE than 100 years ago, the British physiologist Caton (11) recorded electrical waves from the brains of rabbits and monkeys. When he discovered that these potentials were vulnerable to such phenomena as anoxia and anesthesia, he realized that the waxing and waning of the waves was related to the activity of the brain. Some years later and unaware of 
Caton's work, the Polish physiologist Beck (4) performed research on the electrical currents of the cortex of dogs and he described the blocking of the waves at the presentation of a sensory stimulus. However, the extensive research of Beck which was mainly published in Polish, has received little attention. The German psychiatrist Berger (5) extended the method and is nowadays regarded as the father of electroencephalography. He used both animals and humans as experimental subjects and published the first graphs with alpha-waves. Berger introduced also the name Elektrenkephalogramm for the registered signal.

Presently, the recording of the electroencephalogram (EEG) is one of the most frequently applied methods in brain research. Ample evidence exists that the EEG is generated by excitatory and inhibitory synaptic potentials of large population of neurons. The summed electrical activity of numerous nerve cells results in a field potential which penetrates the brain surface and can be measured on the scalp. It is assumed that the main contribution to the scalp recorded EEG stems from numerous neurons located in cortical layers and particularly from large pyramidal neurons perpendicularly directed to the cortical surface, with extended dendritic arborizations in superficial layers parallel to the cortical surface $(10,55,59)$. How the EEG characteristics of the various sleep-wake states are composed by the potentials of large numbers of individual neurons is still under study. In this paper, the correlation of patterns between the EEG recorded from the scalp and the underlying neuronal activity, is investigated for the conventionally distinguished sleep-wake states. Implications of changes in neuronal activity for the processing of information during these states are also discussed.

\section{NEURONAL ACTIVITIES AND THE ELECTROENCEPHALOGRAM}

Most research on the neuronal basis of the EEG is performed in lower mammals such as cats and rats. Basically, these animals show a relationship between EEG and vigilance to that in primates and humans. This means that active wakefulness is accompanied by low amplitude high frequency (beta) waves in the EEG, whereas the EEG of slow wave sleep is composed of high voltage, low frequency (delta) waves. The pattern of alpha waves, in humans characteristic for a relaxed awake state, does not occur in these lower animals. On the other hand, spindle transients with a frequency of 12 to 14 $\mathrm{Hz}$, in humans associated with the shallow sleep of Stage 2, appear in animals not only during light slow wave sleep, but also during the waking state just before entering sleep (72). Related to spindle activity are aberrant phenomena such as spike-wave discharges; these epileptic paroxysms often occur in both the human and the animal EEG. A prominent pattern in the EEG of cats and rats is theta-rhythm, but this pattern originating in the hippocampus, relates in a different way to behavior than theta EEG waves in humans. In the latter species these waves transiently occur in EEG recordings at the border of sleep, while in cats and rats the main behavioral domains of hippocampal theta-rhythm are active wakefulness and rapid eye movement (REM) sleep $(12,69)$.

Steriade and colleagues (60-65) have performed extensive research on the state of nerve cells during sleeping and waking. During waking, thalamic and cortical cells are in a state of tonic depolarization with relatively stable membrane potentials of around $-60 \mathrm{mV}$. Neurons fire in a tonic or relay mode, implying a sustained and high spontaneous activity (32) (Fig. 1). This variable discharge pattern with a low synchronization between cells, is the reason why EEG electrodes, which summate the electrical activity of numerous cells, only record small, but irregular and heavily fluctuating waves. The tonic mode of firing is the substrate of beta waves. The occurrence of spindles marks the transition from wakefulness to sleep. Spindles become manifest when thalamocortical cells undergo a moderate hyperpolarization with a membrane potential lower than - $60 \mathrm{mV}$ (51) (Fig. 2). Longlasting hyperpolarizations are regularly interrupted by rebound bursts of highfrequency spikes; a pattern that is measured as spindling by EEG electrodes. This mode of activation characterized by rhythmical fluctuations of the voltage of cell membranes, resulting in pause-burst discharges of many cells, is called an oscillatory or burst mode. Researchers are convinced that the origin of spindle oscillations is located in the thalamus, but the mechanism of generation is subject of disagreement. Andersen and Andersson (2) postulate that intrinsic properties of a thalamic network can lead to spindling with a main role for inhibitory interneurons, while Steriade and Buzsáki (61) claim that neurons in the thalamic reticular nucleus possess pacemaker properties.

Related to spindles are aberrant phenomena often occur-
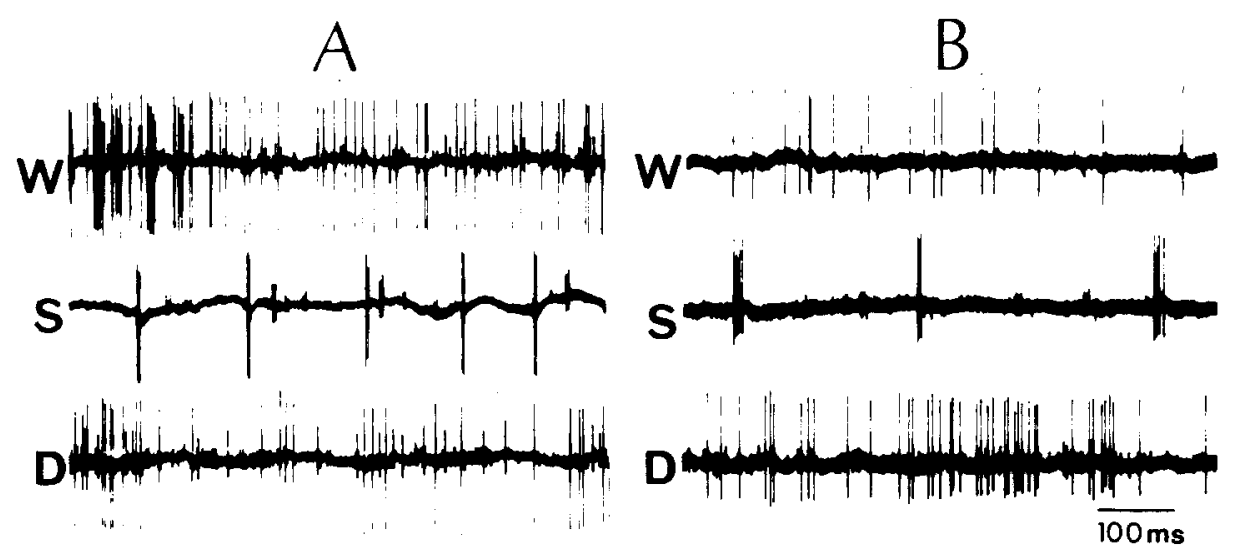

FIG. 1. Extracellular recordings of spontaneous activity of two thalamocortical neurons of the cat (A and B), during waking (W), slow wave sleep (S) and REM sleep (D). Note the high tonic activity during waking, and in particular during REM sleep. Observe also the low burst-like activity during slow wave sleep. [Adapted from Glenn and Steriade (32)]. 


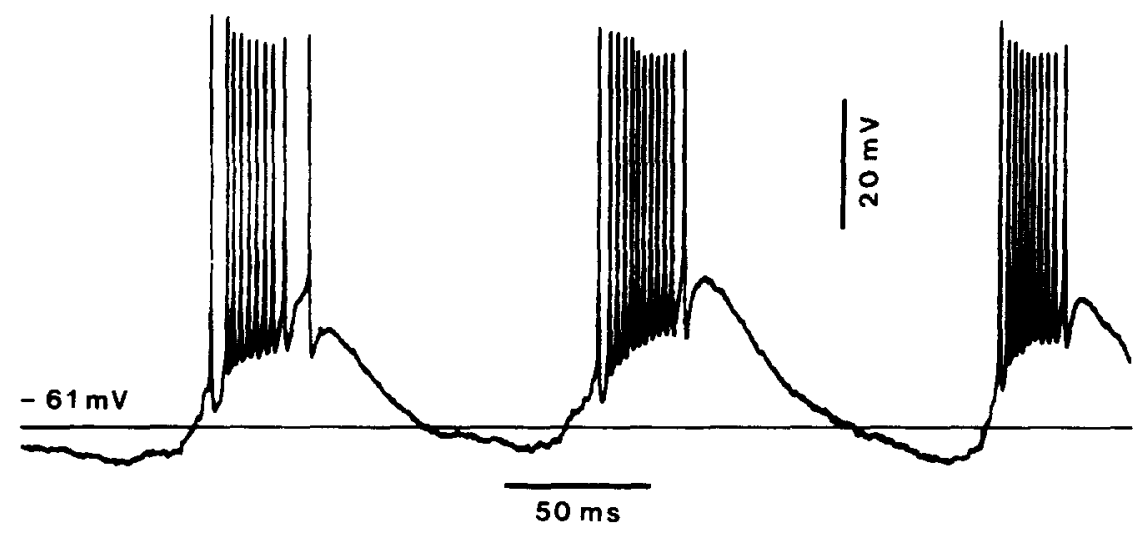

FIG. 2. Intracellular recordings of a neuron in the thalamic reticular nucleus of a cat under barbiturate anesthesia. Spindle sequences are facilitated by the barbiturate. Following a prolonged hyperpolarization of under $-61 \mathrm{mV}$ a rebound burst discharge is generated. [Adapted from Mulle et al. (51)].

ring in the EEG of animals. These are called spike-wave discharges $(50,71)$ or high voltage spindles (9). Amplitudes and frequencies of the large spikes in these discharges are almost identical to spindles; a clear exception is that these spikes are sharper and asymmetrical (28) (Fig. 3). In humans these discharges are characteristic and indicative of epileptic absence seizures, with mild symptoms as immobility and a decrease in responsiveness. These phenomena do not seldom occur in small laboratory animals such as white rats. There is evidence to consider these aberrant transients as modified spindles. Arguments for this view are derived from their morphology and also from the fact that in rats spike-wave discharges as well as spindles occur under identical states of vigilance, such as relaxed wakefulness and light slow wave sleep $(17,26)$. The relationship between spindles and spike-wave discharges has also been suggested for cats $(3,44)$, as well as for humans (42). In the transition from wakefulness with its low voltage high frequency beta waves, to sleep with its large amplitude, low frequency delta waves, spindle activity can often be noticed. This suggests a role for spindles or the underlying neuronal activity in this transition. A high sleep propensity, produced by a prolonged sleep deprivation, facilitates the transition to sleep. It is worthwhile to note that Drinkenburg et al. (25) have shown in sleep-deprived rats that during fast transitions from waking to sleeping a short spindle-like burst can often be observed (Fig. 4).

Thalamocortical relay neurons are also involved in the production of delta waves. These high voltage, irregular and low frequency waves of deep slow wave sleep, become manifest when neurons undergo a still further hyperpolarization to
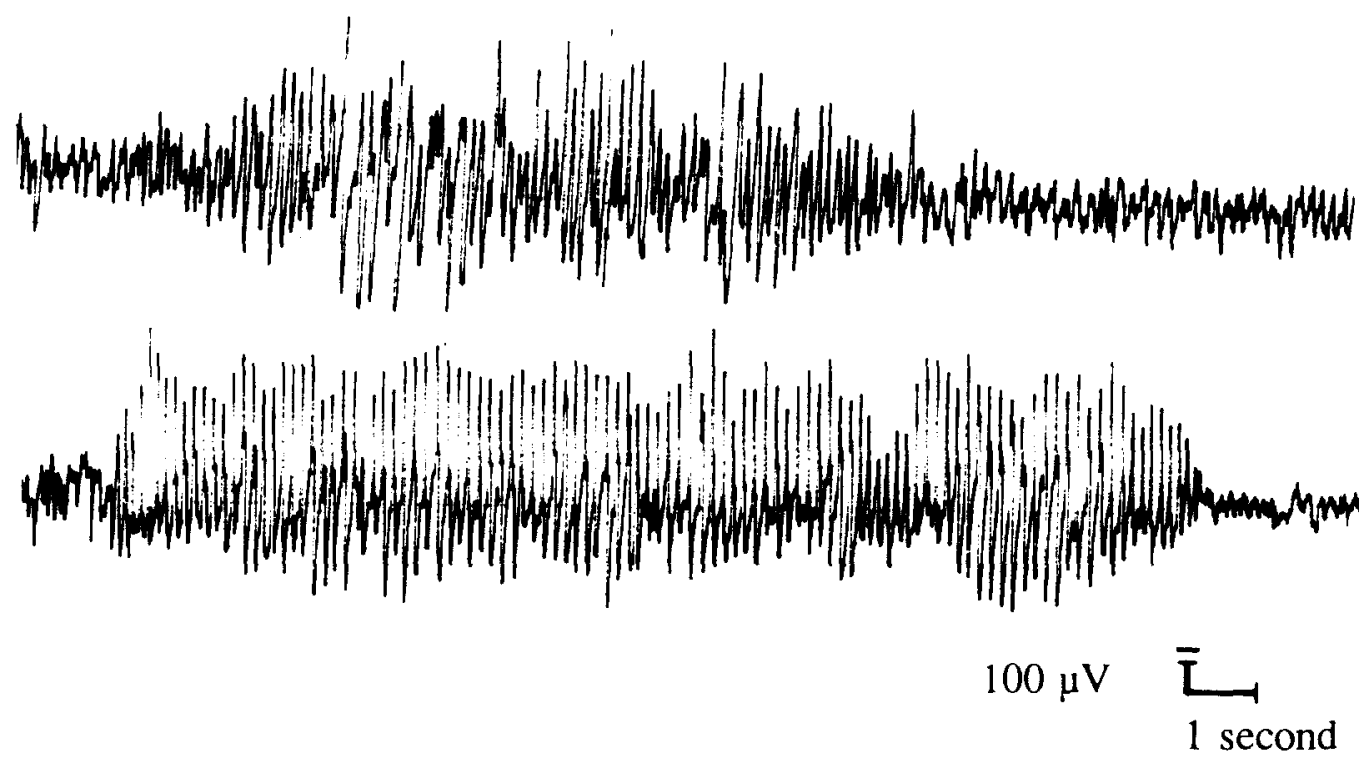

FIG. 3. Representative spindles and spike-wave activity in the EEG recorded from the frontal cortex of a rat. In the top trace normal, physiological occurring spindles are shown. Those presented here appear in the "intermediate stage" of sleep, which is a brief state of sleep heralding REM sleep (34). In the bottom trace a typical spike-wave discharge is presented. Note the sharp, large, negatively directed spikes. [Adapted from Drinkenburg et al. (28)]. 


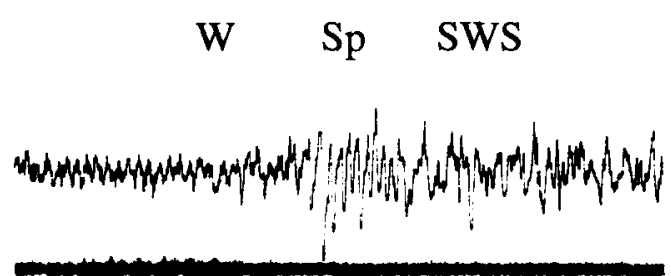

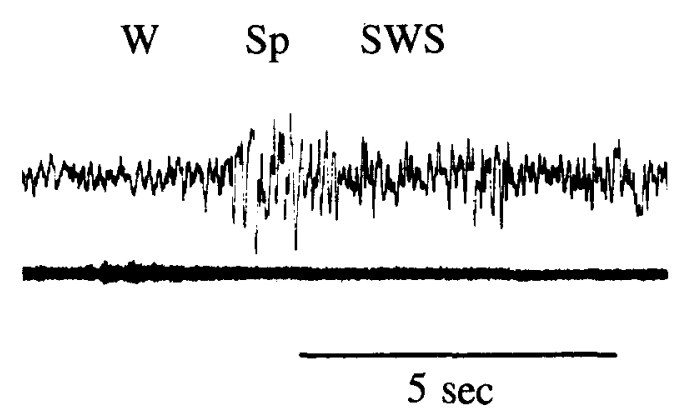

FIG. 4. The cortical EEG (top trace), together with the neck mucle electromyogram (EMG) (bottom trace) is recorded in a sleep deprived rat. Two fast transitions of waking (W), accompanied by small twitches in the EMG, to slow wave sleep (SWS) are shown. Note the short spindle bursts (Sp), which mark the transition between the small amplitude, high frequency (beta) waves of wakefulness and the large amplitude, low frequency (delta) waves of sleep. [Reproduced from data derived from Drinkenburg.]

about -70 till $-90 \mathrm{mV}$. Delta waves have a large amplitude, which implies that extended populations of neurons fire rather synchronously, interspersed with prolonged hyperpolarizations. In contrast to spindles, these waves are not rhythmical but highly irregular $(19,53,65)$.

Ample evidence is available that REM sleep is controlled by the pontine reticular formation. The ponto-geniculooccipital (PGO) waves originating in this area, are involved in activating the thalamocortical relay cells and bringing them in the tonic firing mode. As during waking, these neurons become tonically depolarized and spontaneously exhibit considerable activity, which often is even higher as compared with the waking state (Fig. 1, Fig. 5). Hirsch et al. (38) have established that the maximal difference in membrane potential of the cells between slow wave sleep and REM sleep is about 10 $\mathrm{mV}$. Although the high spontaneous activity of REM sleep is not limited to the sensory areas of the cortex but also include the motor areas, the activity of the latter part is not expressed at a bodily level. A deep hyperpolarization of neurons in the peripheral motor system is the underlying mechanism for muscular relaxation (33). With exception of the tiny muscles of eyes and extremities, all muscles are relaxed. This mechanism prevents gross overt movements during REM sleep.

\section{THE TRANSFER OF INFORMATION}

Sensory systems react to environmental stimuli, encode all information in electric impulses and convey this coded information over the sensory pathways to the thalamus. Series of impulses carrying all aspects of information reach the thalamocortical relay cells. Using intracellular recordings of cells in the lateral geniculate body of the cat, Coenen and Vendrik (15) have shown that during wakefulness the ratio between output and input of a thalamic relay cell, the transfer ratio, is almost one (Fig. 6). This implies that action potentials of a retinal ganglion cell produce excitatory postsynaptic potentials (EPSPs), which easily pass the low-level threshold of the tonic firing mode and generate outgoing action potentials. The transmission occurs in a way of one input to one output action potential. This means that the complete message as coded by the peripheral receptors, reaches the sensory parts of the cortex in its entirety.

When the animal becomes drowsy the transfer ratio goes down till about 0.7 , for the reason that the output decreases while the input remains identical. A decline of the processing of information becomes manifest when the states of drowsiness or light slow wave sleep, both characterized by spindle transients, appear. An increase of the hyperpolarization of

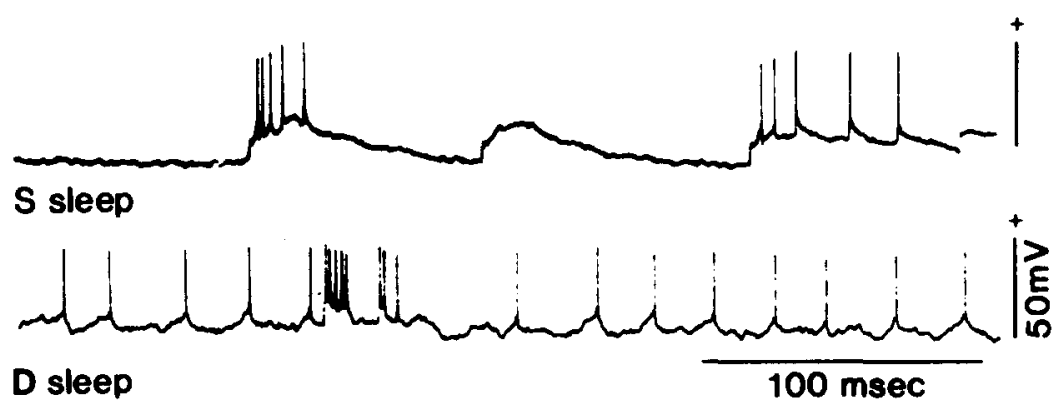

FIG. 5. Membrane potential and spontaneous activity of a neuron in the lateral geniculate body of a cat. Recordings were made during slow wave sleep ("S sleep," upper trace) and during REM sleep ("D sleep," lower trace). During slow wave sleep the membrane potential is low and the irregular activity is composed of isolated excitatory postsynaptic potentials (EPSPs) and large depolarizations with or without bursts of spikes. In contrast, during the tonic depolarized state of REM sleep, action potentials arise from small depolarizations, and the activity is higher. [Adapted from Hirsch et al. (38)]. 


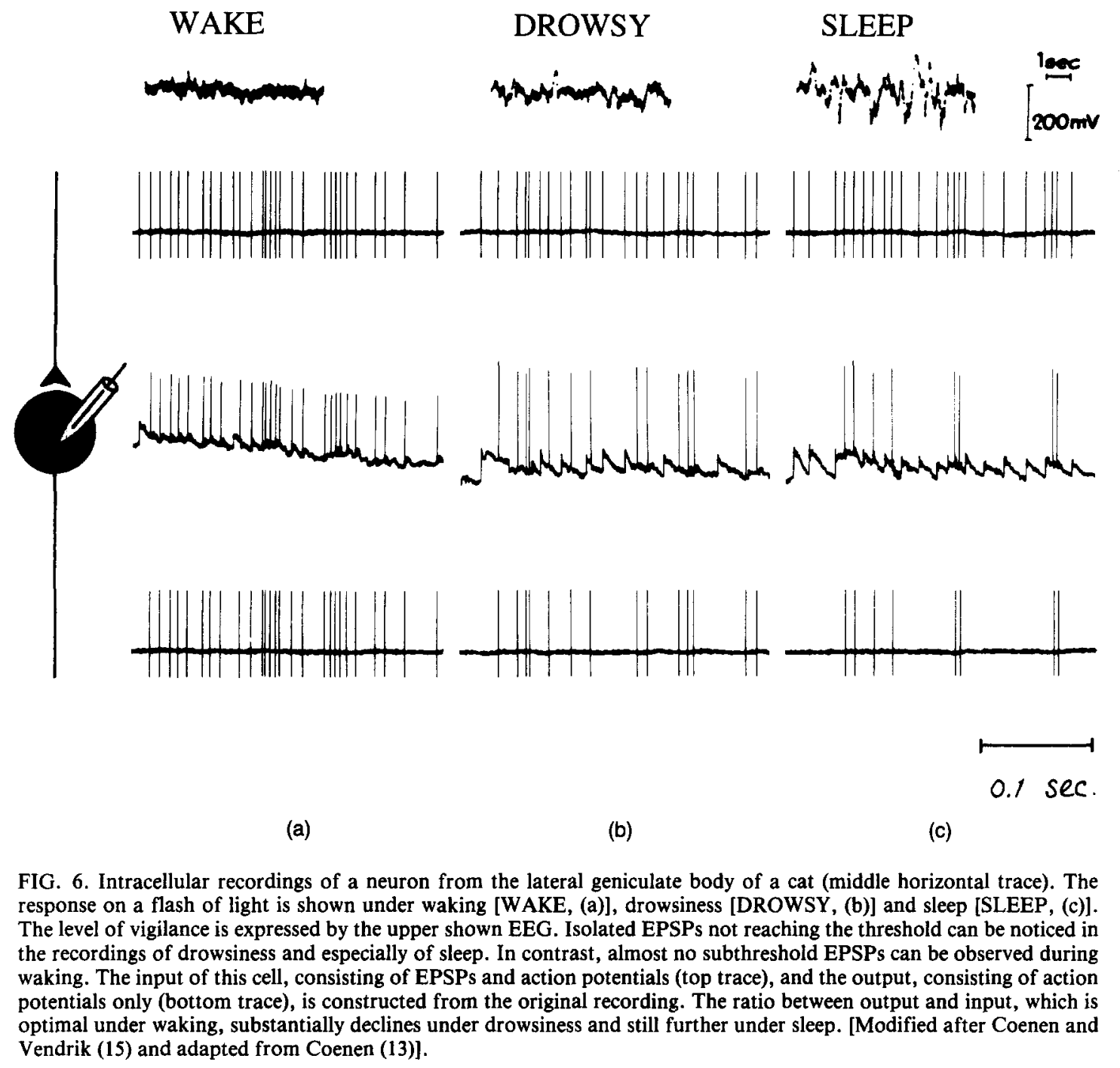

thalamic neurons results in an inability of the EPSPs produced by the incoming action potentials to reach the increased threshold. Presently, Steriade (60) and Steriade and McCarley (62) have convincingly demonstrated that a depolarization of the membrane potential is the cause of the decrease of the transfer ratio and that it is not a modulation of the amplitude of the EPSPs, as originally suggested by Coenen and Vendrik (15). The burst mode in which the system fires, continuously blocks a major part of the afferent information at the thalamic level. Steriade et al. (65) describe this as following: "when thalamic networks are in the rhythmic burst firing mode, their response to afferent stimulation is often a stereotyped oscillation, the characteristics of which are determined by the properties of the constituent neurons and circuits and not by the properties of the afferent signals." Recordings of cells in the lateral geniculate body of the cat both during slow wave sleep and wakefulness clearly show this phenomenon (16) (Fig. 7) and Livingstone and Hubel (48) extended these findings for the primary visual cortex of the cat. The blocking of the incoming series of spikes becomes even stronger when the organism enters into deep slow wave sleep. In this state which is accompanied by delta waves, the transfer ratio drops further to about 0.3 or 0.4 . When the animal is awakened, the transfer ratio immediately returns back to about one (Fig. 8). This was confirmed by Singer (57) by electrical stimulation of the activating reticular system of a cat which also causes an arousal response. In this way, he was able to elicit an immediate increase of the transfer ratio. Singer (58) could also demonstrate that electrical stimulation of the rostral part of the brainstem was associated with a reduction of intrathalamic inhibition and with an induction of a depolarized state in cells of the lateral geniculate body, initiating a high and sustained spontaneous activation and an opening of the sensory channels. This facilitation of the transfer of impulses is controlled by the activating reticular system of the brainstem.

These experiments indicate that during sleep, just as during wakefulness, the sensory organs transform sensory stimuli in series of impulses. They also show that during the state of sleep, the blocking process in the thalamus ultimately leads to the arrival of only few spikes at the level of the sensory cortex. It might be possible that the amount of information passing through the thalamus during sleep is just enough for a shallow, subconscious, evaluation. From classic experiments it is for example well-known that the threshold for awakening is lower for a relevant stimulus than for a physical identical stimulus which has no relevance for the individual $(7,47$, 

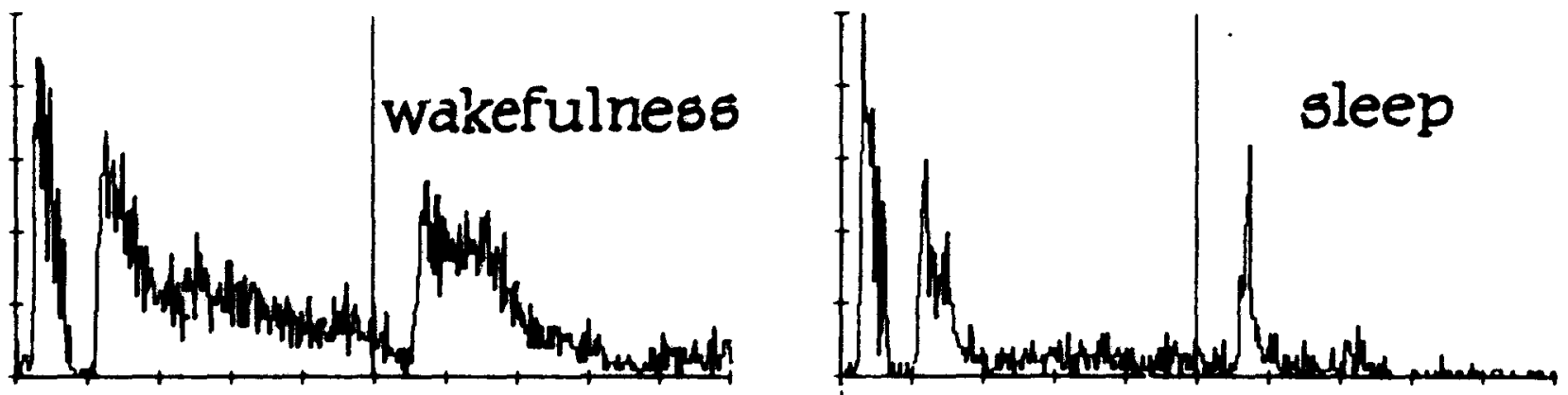

10 spikes/bin

$100 \mathrm{msec}$

FIG. 7. The effects of wakefulness (left) and sleep (right) on the responses, expressed in PSTHs, of a lateral geniculate on-cell of the cat. The response on light on (flash of $500 \mathrm{msec}$, left part of each PSTH), and light off (flash of $500 \mathrm{msec}$, right part of each PSTH) is shown. Mark the smooth and tonic character of the response under waking and the phasic, spiky and more time-locked response under slow wave sleep. [Adapted from Coenen et al. (16)].

$54,75)$. In concordance, we have shown that during the occurrence of spike-wave discharges in rats a certain degree of evalution of incoming stimuli still takes place (27). When physically identical stimuli with differential impact, induced by previous conditioning, are offered during the presence of a spike-wave discharge, the relevant stimulus terminates this activity more frequently than the less relevant one. This not only means that during this aberrant state some sensory activity reaches the sensory cortex, but also that the brain still has the ability to evaluate this activity.

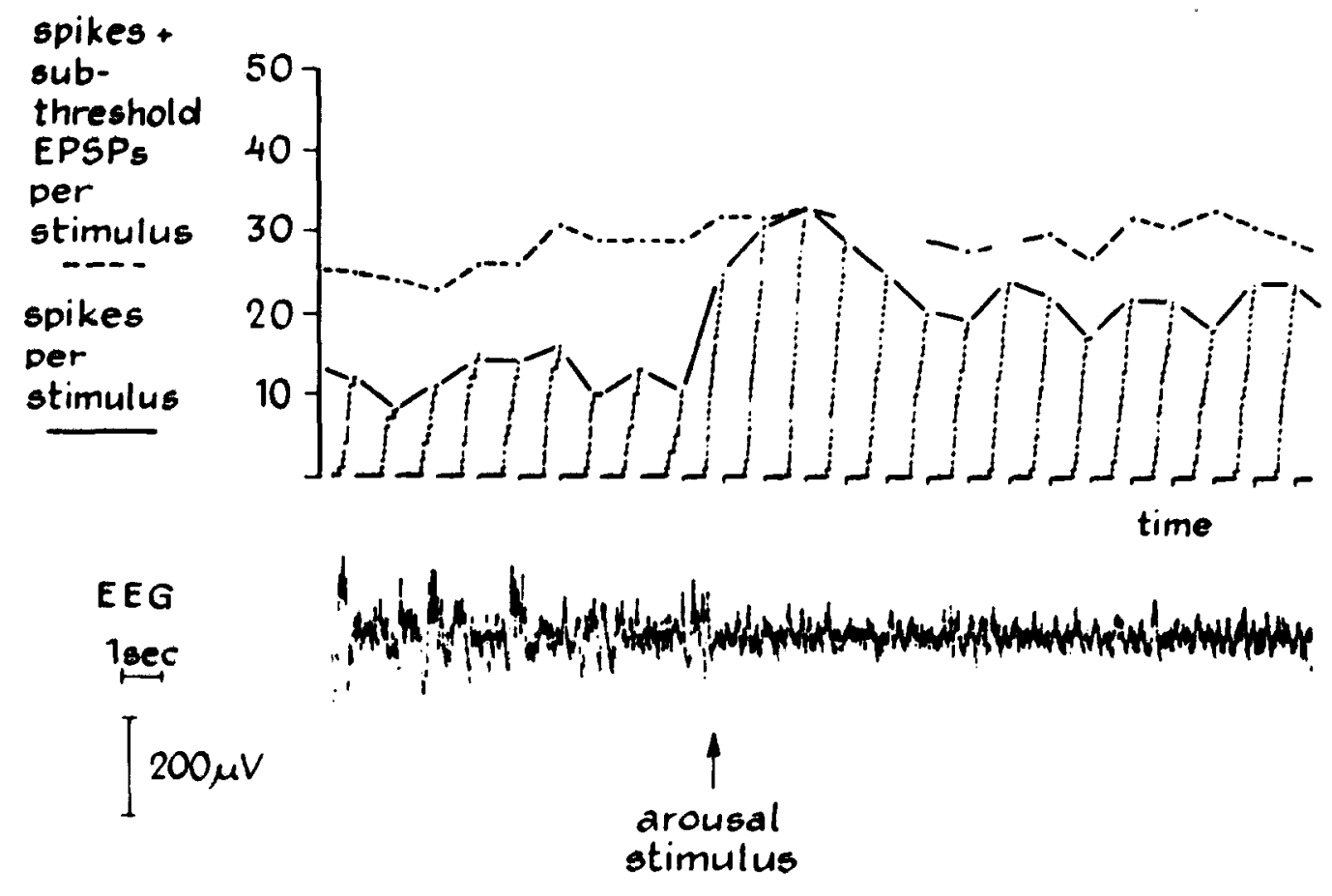

FIG. 8. Responsiveness of a neuron in the lateral geniculate body of a cat to visual stimuli. A flash is given every second and the vertical lines represent the spike response of the cell. The upper, horizontal interrupted line indicates the input of the cell, consisting of spikes and subthreshold EPSPs, whereas the lower horizontal striped line represents the output of the cell, consisting of the number of spikes per stimulus. Following an arousal stimulus to the cat (arrow), the sleep EEG desynchronizes into a wake EEG, which is accompanied by an increase of the spike response to the flash. At that point the transfer ratio increases from about 0.5 to about 1 , shortly later followed by a small decline to 0.7 or 0.8 . [Adapted from Coenen and Vendrik (15)]. 

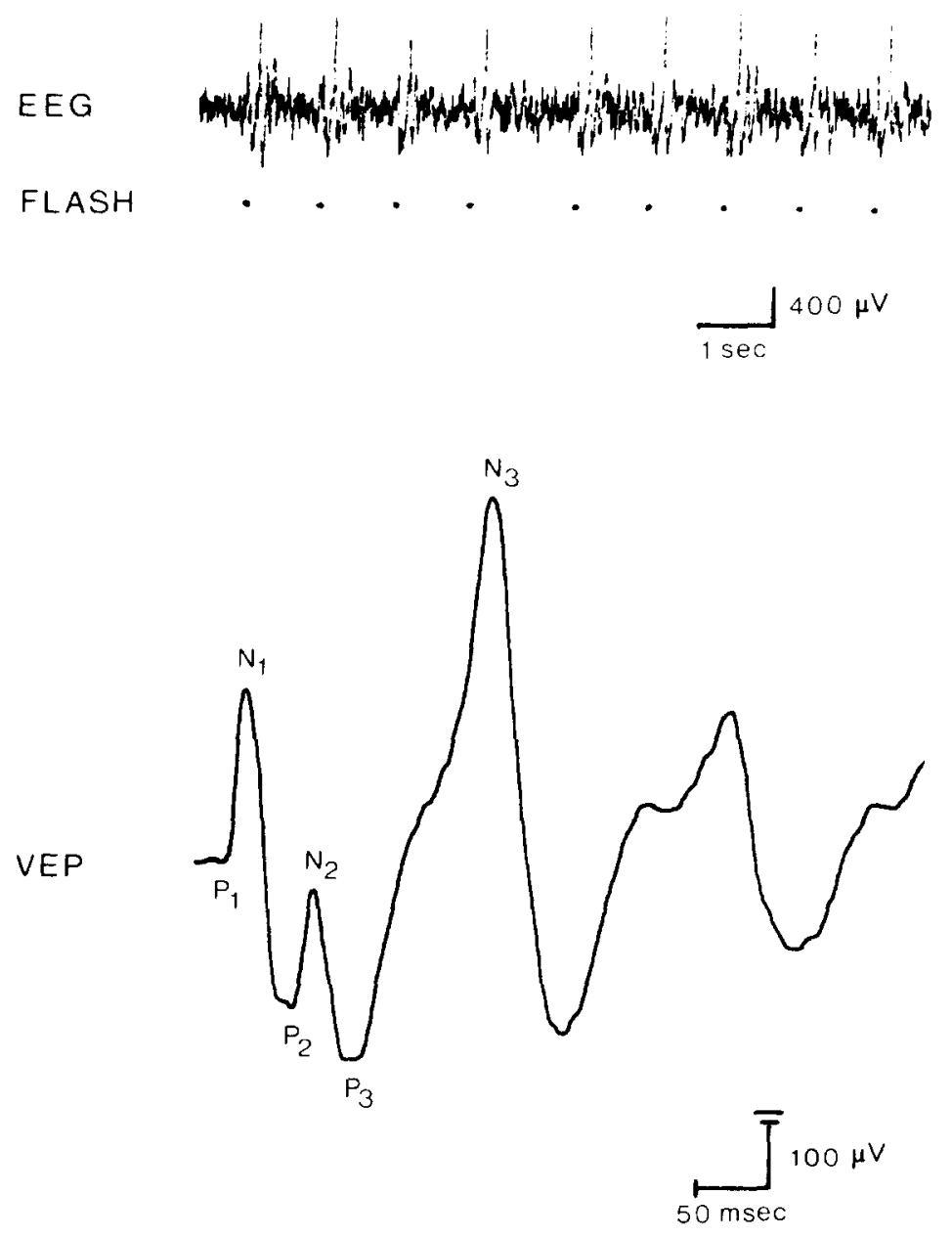

FIG. 9. A representative averaged visual evoked potential (VEP) of a rat (bottom). The single evoked potentials elicited by flashes which are indicated by points, can be distinguished in the cortical background EEG (top). As usual, negativity in the EEG is directed upwards. [Adapted from Van Hulzen and Coenen (70)].

At this time the transfer ratio of REM sleep has not been determined. Nevertheless, anecdotal data can be gathered, suggesting that this ratio varies with the fluctuating threshold of awakening during REM sleep. Presumably, the ratio is not far from one when the awakening threshold is low at the end of a REM sleep period. Evidence in favor of this view is the presence of a depolarized state of the neurons analogous to waking (62) and further the identical shape of visual evoked potentials made during REM sleep and waking (70). Obviously, a depolarized state of thalamocortical cells is a necessary condition for perceptual processes such as occur during waking and dreaming, the latter being associated with REM sleep. On the other hand, some evaluation processes are still possible when the level of consciousness is low, such as during slow wave sleep and during the occurrence of spike-wave activity. Thalamic blocking is associated with a decline in the level of vigilance and consciousness. The neuronal organization responsible for thalamic gating thus seems related to consciousness or at least to a decline in responsivity.

\section{NEURONAL ACTIVITIES AND EVOKED POTENTIALS}

If we regard the spontaneous EEG as a window on the functioning of the brain, this window can be opened by the responses of the EEG to external stimuli. The responses on stimuli such as brief flashes of light or clicks are known as evoked potentials (Fig. 9). The first description of such a timelocked potential came from Davis (20) and his group (21), who studied the influence of the state of vigilance on potentials elicited by auditory stimuli. In general, the amplitude of evoked potentials is low, whereas the fluctuations in the background EEG are substantial. Dawson (22) introduced an averaging procedure to increase the signal to noise ratio. $\mathrm{He}$ did this by determining the mean potential of a large number of single evoked potentials elicited by the same stimulus. It is this procedure that has become a powerful tool in the hands of psychophysiologists. An averaged evoked potential, or event related potential (ERP), is composed of a series of large, biphasic waves, in total lasting about 500 to $1000 \mathrm{msec}$. Com- 
monly, the ERP is divided in early and late components, with the line drawn somewhere around $100 \mathrm{msec}$. The early waves are determined by the physical qualities of the stimulus, such as intensity and duration, while the late components are strongly influenced by endogenous factors, such as the attention directed to the stimulus and to subsequent information processing activities. This also means that these late components are in particular sensitive for the degree of alertness. This implies that the shape of an ERP, irrespective of its modality and just as its substrate the background EEG, is dependent of the state of the brain.

One of the first animal studies to the effects of sleeping and waking on the ERP was performed by Hall and Borbély (37). They recorded click-evoked potentials in several parts of the rat brain. Van Hulzen and Coenen (70) registered the visual ERP in the cortical EEG of the rat during the three main states of alertness (Fig. 10). It is remarkable that the ERP produced during REM sleep is almost similar to that obtained during wakefulness, which again underlines the consonant characters of these brain states. In contrast, the ERP derived during slow wave sleep reveals the differential nature of this state. The most striking distinction is the shape and amplitude of the N1-P2-N3 complex. This complex is substantially larger in amplitude during slow wave sleep, while the small N2-P3 complex on the slope of the large P2-N3 wave, is no longer observable. The increased synchronization of thalamocortical unit discharges during slow wave sleep is expressed in an enlargement of evoked potential components. The stimulus acts
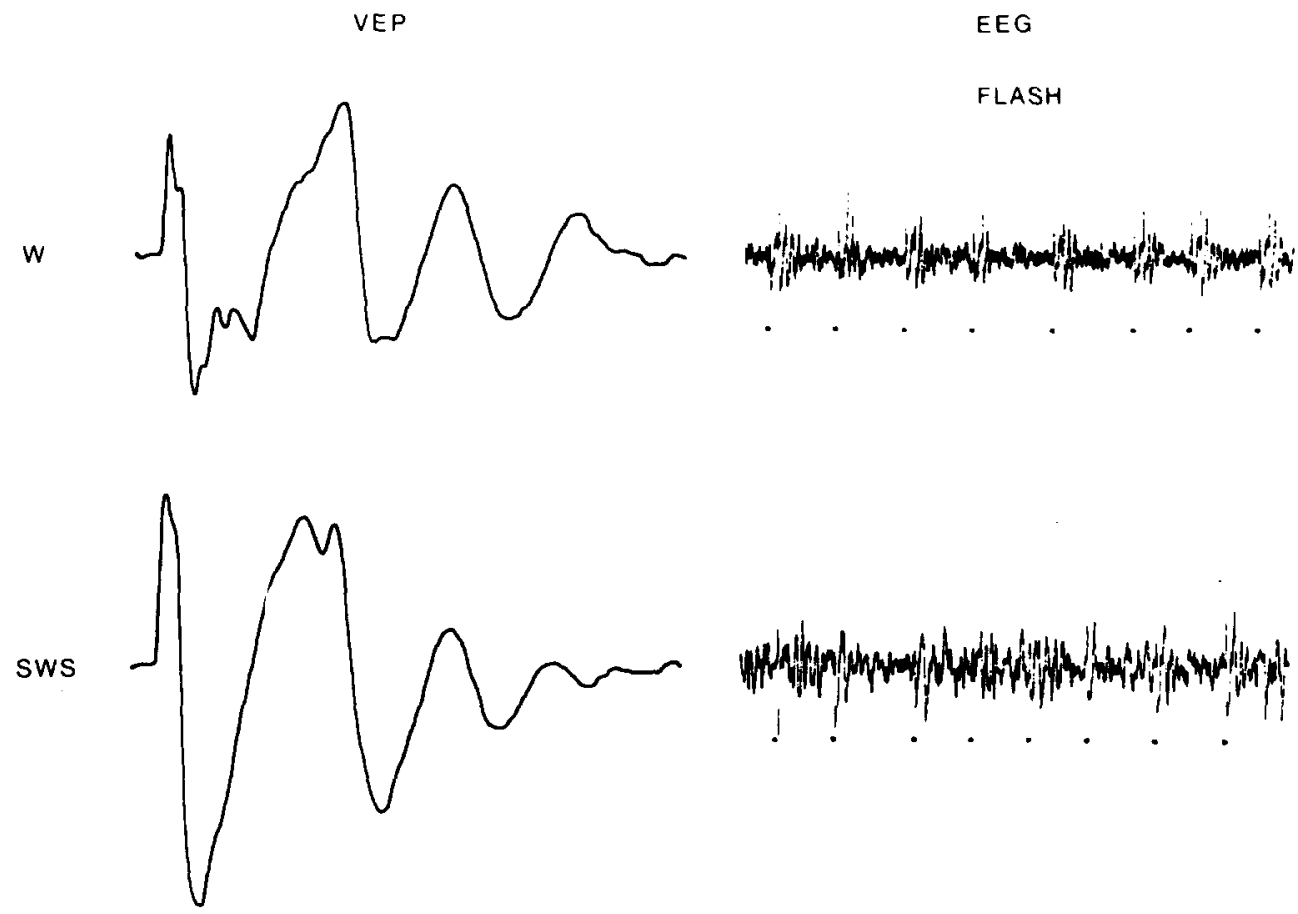

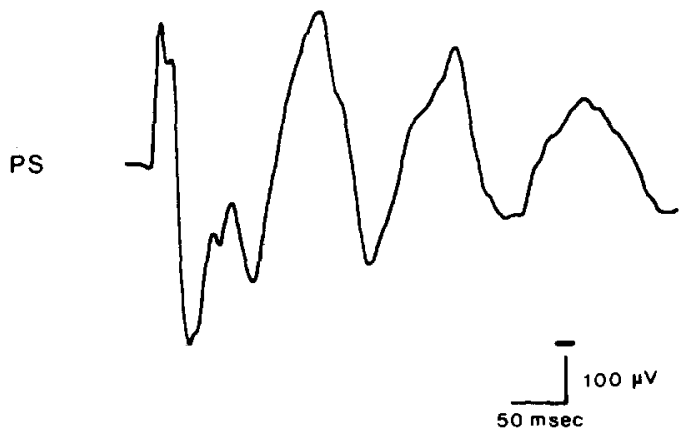

(a)

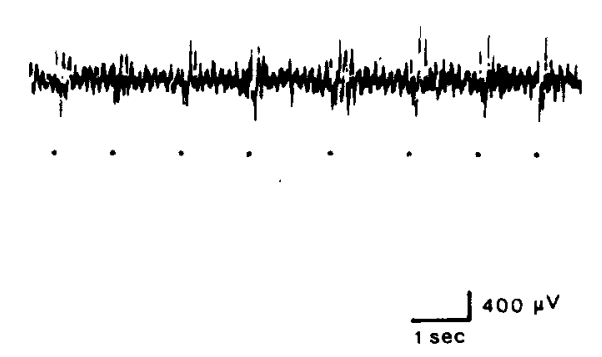

(b)

FIG. 10. (a) The influence of waking (W), sleeping (SWS) and REM sleep (PS) on the shape of the averaged visual evoked potential (VEP) of a rat. (b) The cortical EEGs associated with the states of alertness are presented, together with the individual evoked potentials. Flashes are indicated by points. Note in the VEP the large N1-P2-N3 complex of slow wave sleep and the similarity between the VEP of wakefulness and that of REM sleep. Note also the various background EEGs with the prominent theta-rhythm which indicates REM sleep. Negativity is upwards directed. [Adapted from Van Hulzen and Coenen (70)]. 
as a trigger pulse producing a resonance in the synchronized neural assembly. For the reason that cells are already firing in a bursting mode during slow wave sleep, this resonance is more prominent as that produced by the same triggering of the neural net, when neurons fire in the asynchronous, tonic mode during wakefulness and REM sleep. In the latter situations, the waves of the N1-P2-N3 complex are smaller and less sharp, whereas the tiny N2-P3 complex is manifest (Fig. 10). The response on a flash of a neuron expressed in a poststimulus time histogram (PSTH) is shown for waking and sleeping (Fig 7). It can be observed that the discharge frequency is lower during slow wave sleep. But what is still more relevant for the building of evoked potentials is that the slow wave sleep PSTH is composed of sharper peaks. Both the primary and the secondary excitations are smaller and more timelocked, giving rise to larger amplitude but narrower components in the evoked potential. In concordance, Karmos et al. (41) recorded a PSTH of an auditory cortical neuron on a tone in which a clear increase of the duration of the period of inhibition could be noticed, whereas also the first excitation in these recordings was smaller and more synchronized in time (Fig. 11).

Inoue et al. (40) have registered evoked potentials in the rat EEG during the occurrence of spike-wave discharges (Fig. 12). The visual ERP constructed during these aberrant paroxysms shows similarities with the ERP of slow wave sleep. Mainly responsible for these similarities is the equal N1-P2-N3 complex. There are, however, also differences. The late $\mathrm{P} 4$ component and particularly the afterdischarges are more pronounced under spike-wave bursts. This points to an even more powerful synchronization of cortical cells in comparison with that of slow wave sleep. The problem of how this hypersynchronization is accomplished has still to be elucidated. Whatever the origin may be, spike-wave discharges are caused by an even more time-locked collective firing of numerous neurons in thalamus and cortex.

\section{THE MAKE-UP OF EVOKED POTENTIALS}

In one of the first conferences dedicated to Average Evoked Potentials, under the chairmanship of the pioneers Donchin and Lindsley (24), Vaughan (73) related the shape of a visual ERP measured on the scalp of monkeys to the activity of neurons in cortical layers. Although various exceptions exist, he noticed that the initial biphasic wave was often accompanied by neuronal discharges, whereby the first negatively directed wave was associated with an increase in excitation and the second positive wave with inhibitory activities. In Fig. 13 which is derived from Vaughan (73), a typical on-cell is shown reacting to a flash. To a brief flash however, off-cells also respond which contributes to the shape of the evoked potential. Unfortunately, the current literature provides no example of single unit activity of both an on- and an off-cell together with the superficially recorded visual evoked potential. Flash responses of both kinds of neurons in the visual part of the thalamus of a cat were recorded by Coenen and Eijkman (14), whereas van Hulzen and Coenen (70) and Inoue et al. (40) described visual ERPs of rats. A comparison of these two kinds of recordings (thalamic unit recordings together with a cortical EEG), reveals a striking temporal correspondence (Fig. 14). This figure strongly suggests that N1, the first negative wave of the visual ERP, is comprised of the primary discharges of the on-cells. On the other hand, the positive $\mathrm{P} 2$ is produced by the joint and simultaneously inhibitory actions of both on- and off-cells, whereas the negative N3
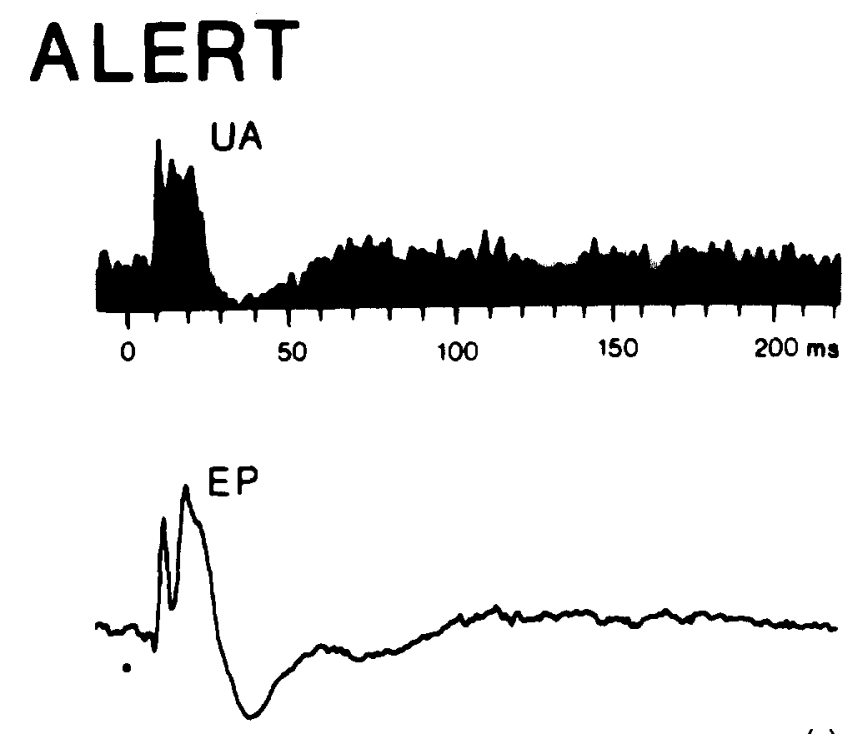

(a)
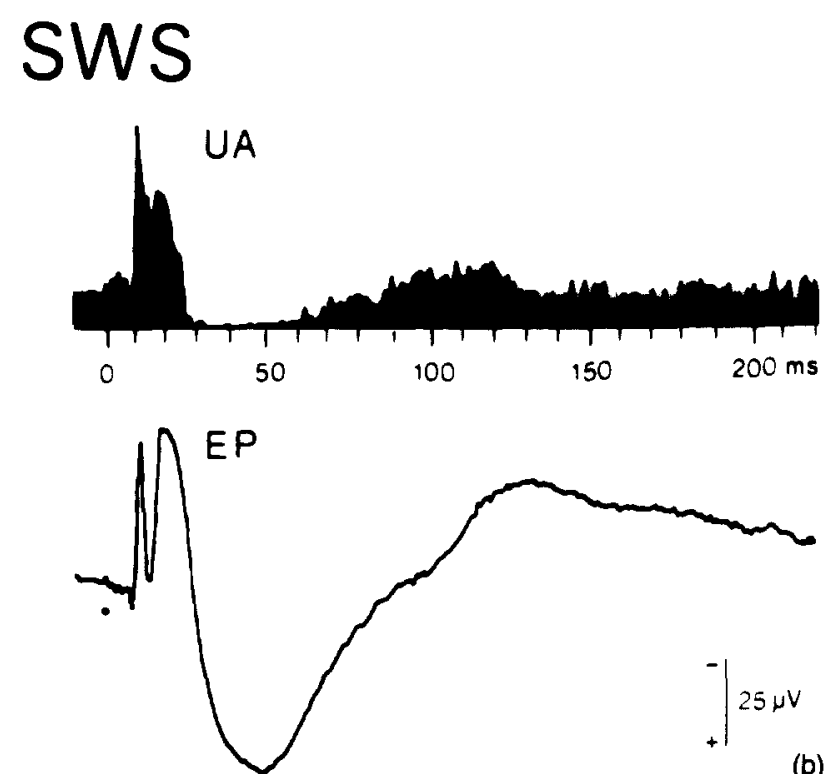

(b)

FIG. 11. Auditory evoked potentials (EP) together with the PSTHresponses of a cortical neuron (UA) of a cat during alert (a) waking and (b) during sleeping. The evoked potential is registered from the upper layers of the auditory cortex of a cat. The longer inhibitory period under sleep, starting $30 \mathrm{msec}$ after stimulus onset, is clearly visible, just as the sharper primary excitation immediately after stimulus onset. This results in larger components of evoked potentials of sleep. [Adapted from Karmos et al. (41)].

is the result of the secondary firing of the on-neurons facilitated by the primary bursts of the off-cells. This view implies that evoked potentials are composed of neuronal discharges which underly negatively directed waves, while neuronal inhibitions are expressed in positive waves.

The neuronal activity underlying spike-wave discharges in rats was studied by Buzsáki (8) and in our laboratory by Inoue et al. (40). Rhythmical bursts of single unit activity concordant 


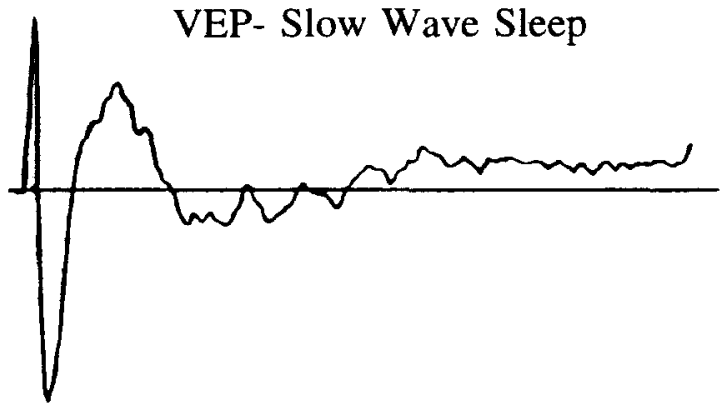

(a)

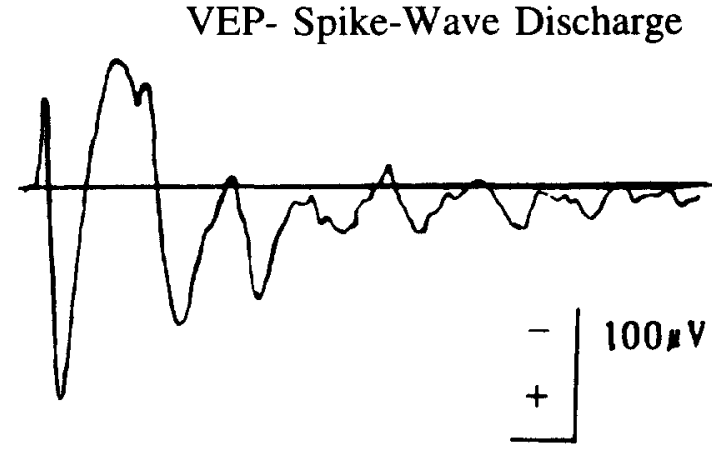

$100 \mathrm{msec}$

(b)

FIG. 12. Visual evoked potentials (VEPs) registered in a rat during (a) slow wave sleep and during (b) the occurrence of spike-wave discharges. Note the prominent late components and afterdischarges in the VEP made during spike-wave discharges. [Adapted from Inoue et al. (40)].

with the spikes of the spike-wave discharges were recorded in the cortex as well as in various thalamic nuclei (Fig. 15). The burst discharges in thalamic neurons clearly preceeded the discharges in cortical cells. This strongly suggests that just as with the genesis of spindles, the thalamus plays a leading role in the configuration of spike-wave discharges. The relationship between neuronal and EEG phenomena illustrated in Fig.

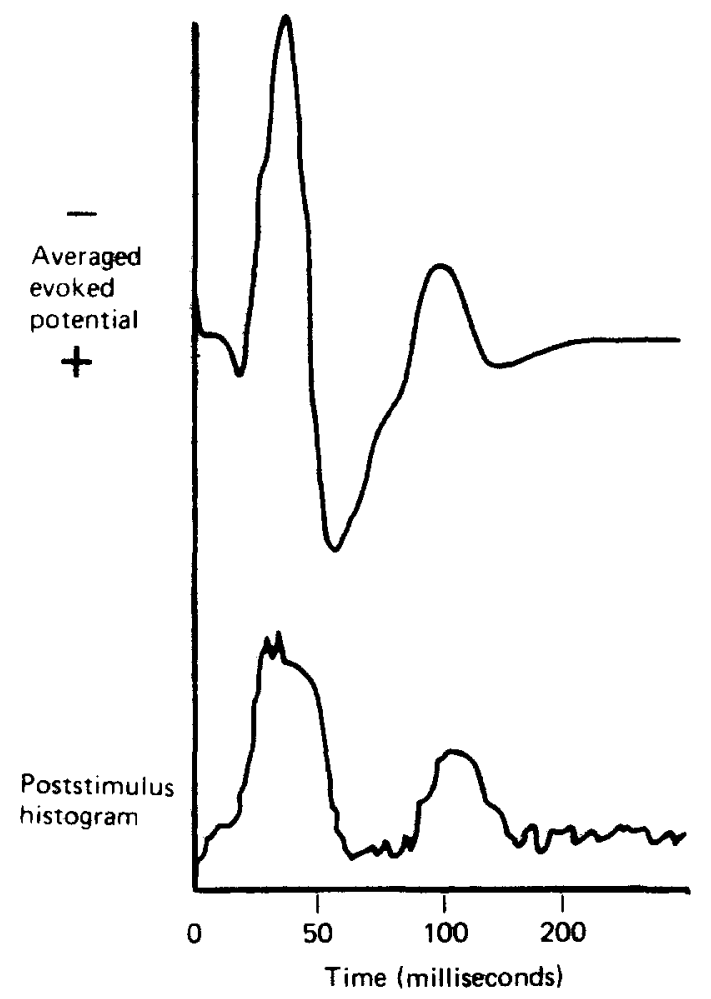

FIG. 13. The response to a flash of light of a neuron in the monkey cortex, expressed in a poststimulus histogram (bottom trace), together with the "averaged evoked potential" from the cortical EEG (top trace). Activity of the cell is related to negativity in this potential. [Derived from Vaughan (73)].

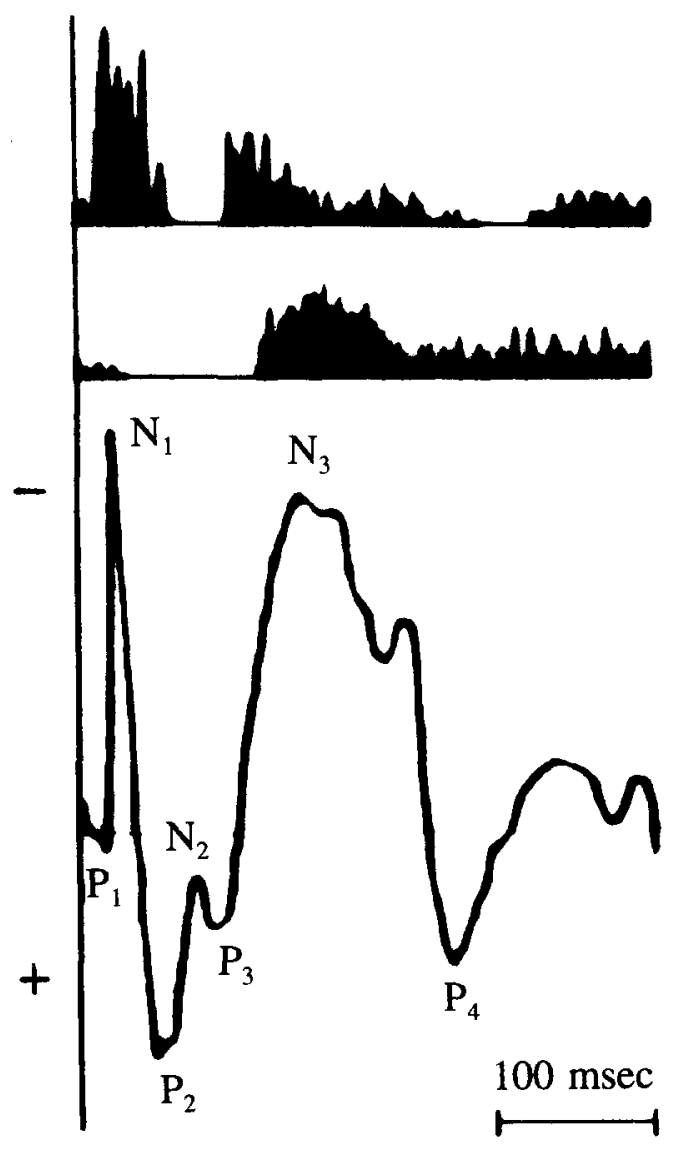

FIG. 14. Responses of two visual thalamic neurons of a cat to light flashes, expressed in poststimulus time histograms (PSTHs). In the upper traces the PSTH-response of both a lateral geniculate on- and off-neuron are shown [taken from Coenen and Eijkman (14)]. In the bottom trace a visual evoked potential of a rat is presented [taken from Inoue et al. (40)]. The temporal correspondence is discussed in the text. 


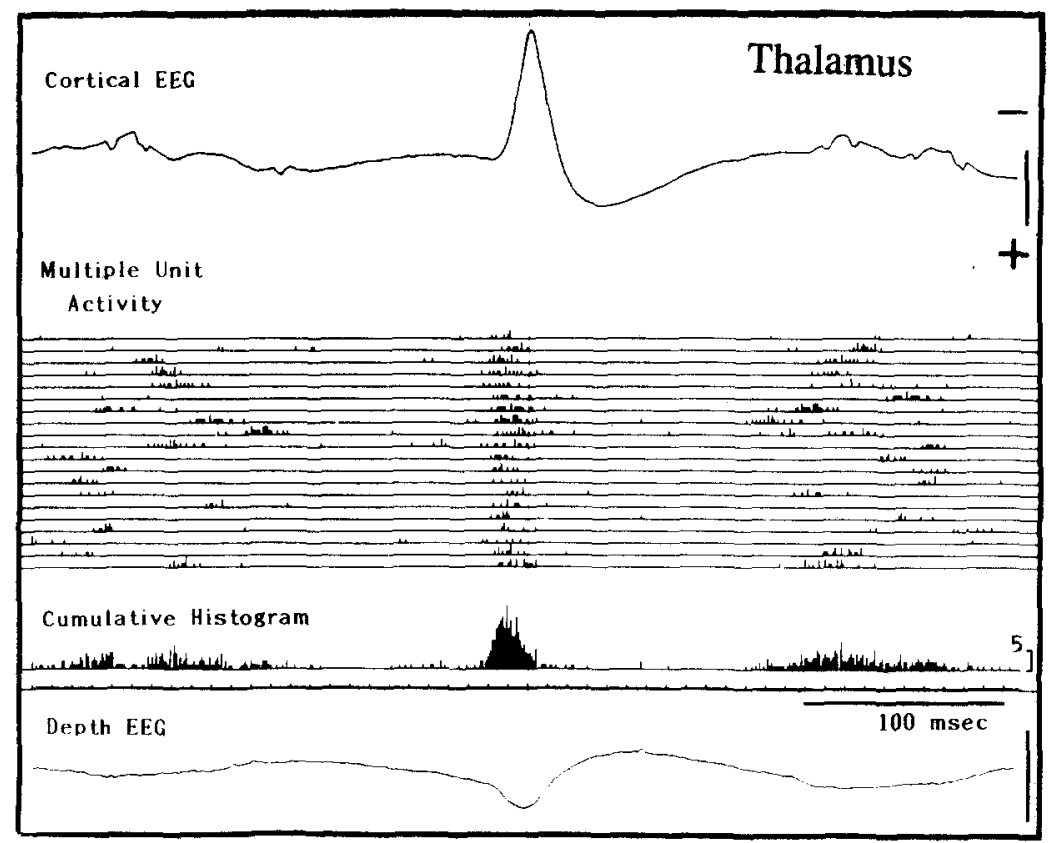

(a)

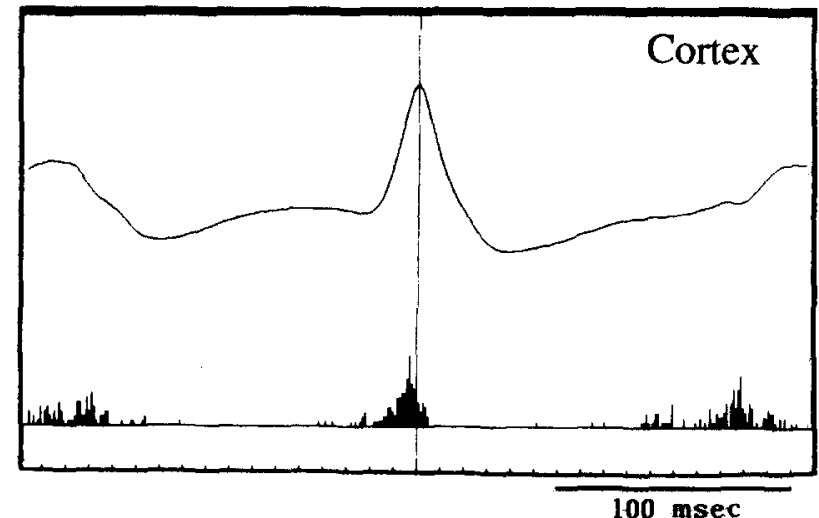

(b)

FIG. 15. Correlation of cortically recorded spike-wave discharges with "multiple unit activity" of (a) thalamic neurons and with (b) cortical neurons. All registrations are from rats and the spike of the spike-wave discharge is taken as a trigger. The "cumulative histogram" of the neuronal activity reveals that cellular firing is related to the large negative spike and that the positive waves preceding and following the spike are related to neuronal inhibitions with cell silence. The figure further shows that thalamic neuronal firing preceeds cortical firing. Note that the polarity of the "depth EEG," registered of deep cortical layers and shown at the bottom of $(A)$, has an opposite polarity compared to the superficial recorded EEG. [Adapted from Inoue et al. (39)].

15 , shows that the large, sharp, negative spikes in a spike-wave burst in the cortical EEG are related to neuronal excitations of thalamic and cortical neurons, while the smaller positive waves are associated with inhibitions of these cells.

The notion about the polarity of transients in the superficial recorded EEG such as ERPs and spike-wave dicharges, with underlying neuronal activities, corresponds with an early observation done by Creutzfeldt et al. (18), shown in Fig. 16. These researchers correlated the waves in the scalp recorded EEG of a cat with synaptic potentials of cortical cells. With this tool, they showed that positivity in the EEG was associated with inhibitory postsynaptic potentials (IPSPs), while negativity in the EEG mainly corresponded with excitatory postsynaptic potentials (EPSPs). Caspers et al. (10) also stated that negative shifts of the cortical slow potential can be conceived as an indicator of cortical activity. Scalp recorded negative shifts have been proposed to be due to depolarizations of apical dendrites of vertically oriented pyramidal cells, creating an extracellular surface current sink.

A model created by Speckmann and Elger (59) provides insight in this relationship (Fig. 17). In this model, large pyramidal neurons with long dendrites perpendicularly directed to the cortical surface are the central elements. Branches of the dendrites, which almost reach the cortical surface, build ex- 

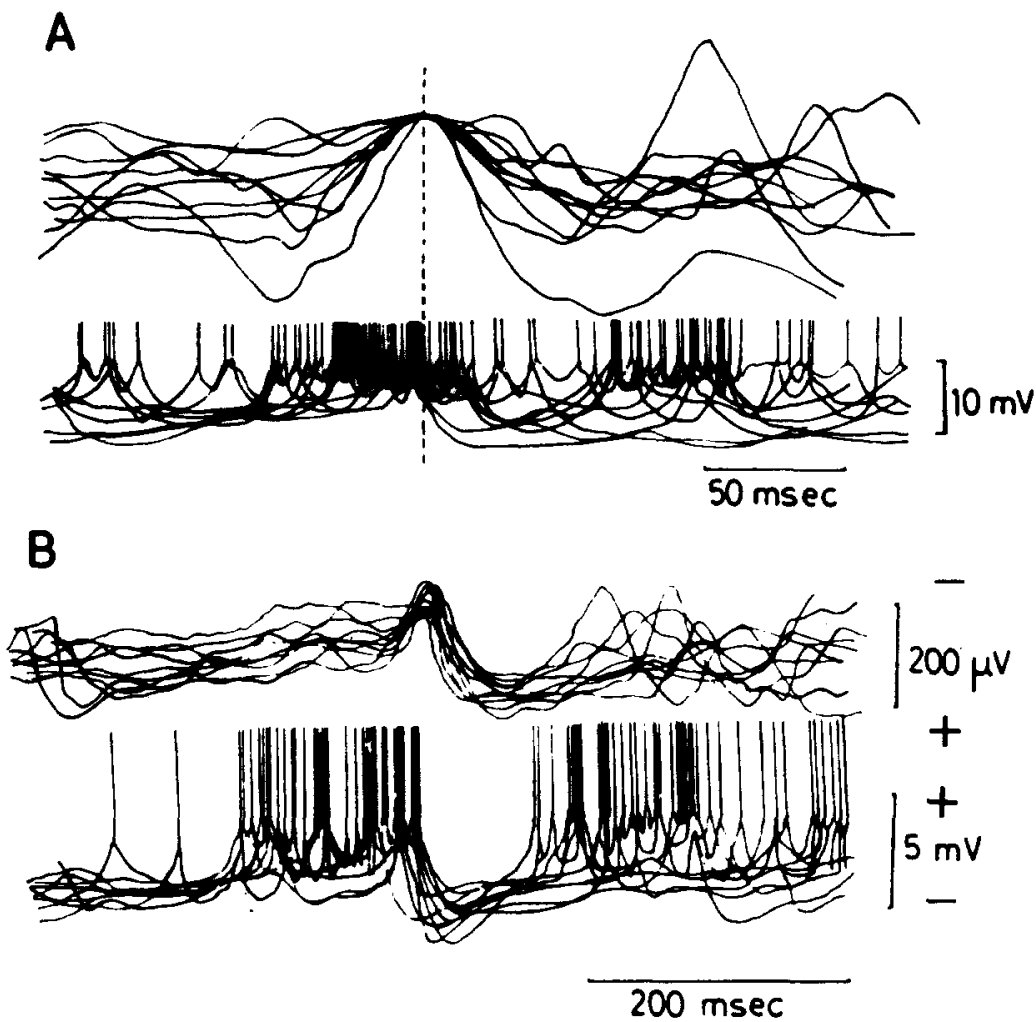

FIG. 16. Correlation between EEG waves and postsynaptic potentials in the cat. EEG waves are superimposed in the top traces of $(A)$ and $(B)$, and the corresponding intracellular events in the bottom traces of (A) and (B). Surface negative waves of symmetrical shapes are selected in (A). Note that these waves correspond best with summated excitatory synaptic potentials. Negative-positive waves are presented in (B). Here, the negative parts correspond again with excitatory synaptic potentials, while the positive components correlate best with synchronized inhibitory synaptic potentials. [Adapted from Creutzfeldt et al. (18)].

tended horizontal arborizations in a layer parallel to the cortical surface. Axonal arborizations of lateral geniculate neurons were actually investigated in the visual cortex of the cat by Ferster and LeVay (30). Figure 18 shows the extension and intensity of the terminal cortical arborizations of one geniculate axon. In superficial cortical layers, numerous axon terminals contact the dendritic woods of the pyramidal cells, forming myriads of thalamocortical synapses (31). According to Speckmann and Elger (59), the synaptic activity in this dense layer gives rise to intracellular positive electrical currents, which extracellularly result in negativity. When these extracellular potentials are measured with EEG electrodes, excitatory discharges are expressed as negative currents, while inhibitory activities are recorded as positive directed currents. From this model it is even plausible that EEG transients have a good correlation with activity in thalamocortical fibers; an activity that originates in the thalamus.

Due to the complex cortical organization, with extensive vertical columnar and horizontal connections, the relationship between the activity of cortical units and EEG transients is often complex. Nevertheless, the upper mentioned correlation as described by Creutzfeldt et al. (18) for thalamocortical neurons and the polarity of EEG transients can often be found, but an opposite one, whereby positive waves are associated with neuronal firing and negative transients with neuronal silence can also be found $(1,45,73)$. Perhaps, the correlation varies with the exact recording place in the cortex, the cortical cell type and its specific location in the complicated cortical network. Common knowledge is that the evoked potential undergoes a phase reversal in deeper cortical layers compared to superficial recordings (e.g., 39,41; Fig. 15); a phenomenon which is also proposed by the model of Speckmann and Elger (59). It is nevertheless of interest to remark here the work of Gray and Singer (35) and Gray et al. (36) in columns in the cat visual cortex, dealing with oscillatory responses in relation to stimulus properties. These high amplitude oscillations with frequencies of $40-60 \mathrm{~Hz}$ in field potentials, are associated with action potentials typically occurring during peak negativity. Llinás and Ribary (49) argue that these oscillations predominantly occur during wakefulness and REM sleep, and point out that thalamocortical neurons play an important role in the generation of these oscillations.

\section{EVOKED POTENTIALS AND COGNITION}

Evoked potentials are currently employed by many psychophysiologists to study human information processing. The premise of this approach is that a selective change in a specific component of an ERP might reveal a change in a specific cognitive process, such as an attention or memory process. An 


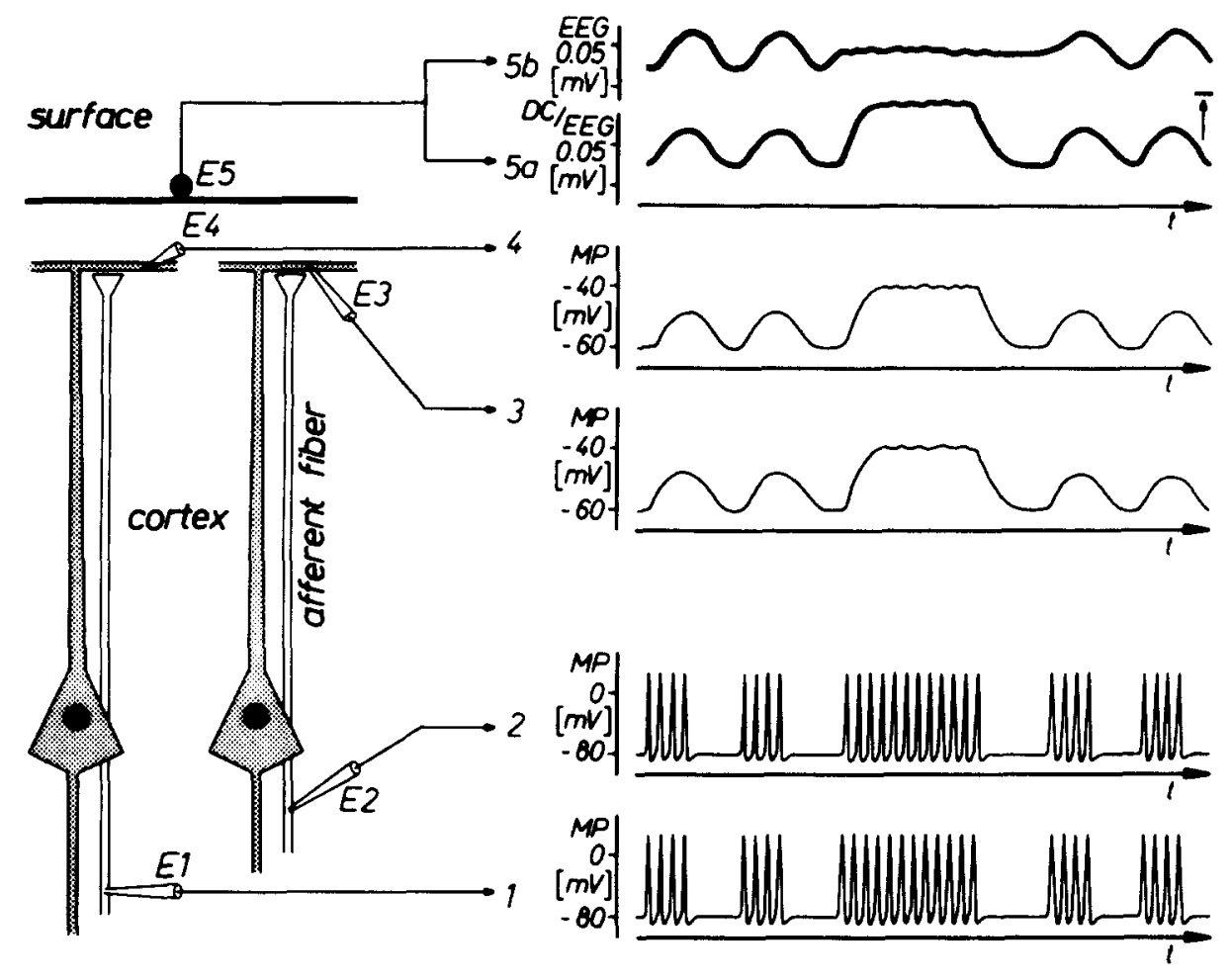

FIG. 17. A model showing the principles of EEG wave generation. The model consists of two large cortical pyramidal cells of vertical orientation, with terminals of afferent fibers projecting on apical superficial dendritic arborizations of these cells. Bursts of action potentials in the afferent fibers (E1-E2) visible in the lower two traces, generate through excitatory synapses depolarizations in membrane potentials (MP) (E3-E4) in pyramidal dendrites. The extracellular field potentials recorded at the cortical surface (ES) have an opposite polarity. A direct current (DC) registration (5a) reflects most accurately all fluctuations in neuronal elements, while a common EEG registration only shows the faster fluctuations (5b). [Adapted from Speckmann and Elger (59)].

often studied evoked potential in relation to cognitive processes is the contingent negative variation (CNV), discovered by Walter (74). A large negativity develops in the cortical EEG when a person expects a certain stimulus to which a reaction is needed. The first stimulus announces a second one, to which a reaction should take place. During the interval between the first and the second stimulus, a slow negative potential gradually develops and this abruptly disappears when the second stimulus is presented. Often, this paradigm is considered to induce a state of brain preparation. Walter (74) had speculated that the CNV reflects an increasing depolarization of cortical dendrites, facilitating responsivity and preparing the cortex for the coming action. This corresponds also with the assumption of Birbaumer et al. (6) and Elbert and Rockstroh (29), that slow negative shifts indicate which areas of the cortex are activated. Timsit-Berthier (68) postulated a neurochemical model for the CNV (Fig. 19). The preimperative negative waveform is regulated by the excitatory neurotransmitter acetylcholine, while the postimperative positive potential, which can be recorded in particular cases, is dependent on a release of the inhibitory neurotransmitter GABA, which produce hyperpolarizations. The Bereitschaftspotential or readiness potential described by Kornhuber and Deecke (46), is a similar EEG phenomenon, also showing a gradual increase in negativity preceding a motor reaction. The general opinion about this potential is that this negative wave reflects motoric preparation. In both examples the final result should be a high effi- ciency of the overt action. When the preparation declines, for example due to sleepiness induced by a prolonged deprivation, the amplitude of the negative CNV wave correspondingly diminishes (52) (Fig. 20). This decreased negativity, or a tendency to positivity, agrees also with the finding of a more hyperpolarized membrane potential as a result of sleep propensity.

The polarity of various ERP components and their underlying neuronal activities suggest that contingent to the increase of diffuse arousal associated with the CNV, cortical neurons increase their firing rates. This can probably be attributed to a heightened tonic depolarization. Thompson et al. (67) mentioned that drugs that increase the degree of arousal or attention, such as caffeine and nicotine, increase the amplitude of the CNV, while drugs which are known to reduce these factors, such as benzodiazepines, reduce them. That stimulants may further enhance tonic depolarization and reduce the neuronal firing threshold, may explain the common finding that reaction times often are faster. The effects on performance and accuracy, however, may differ (43). This may be explained by the fact that the signal to noise ratio cannot be further improved. This, since spontaneous firing may also increase.

An intensively studied component of the ERP is P3 or P300, first observed by Sutton et al. (66). This late component in the ERP appears in response to a rare, task-relevant, stimulus leading to surprise (23). The oddball paradigm is a fre- 


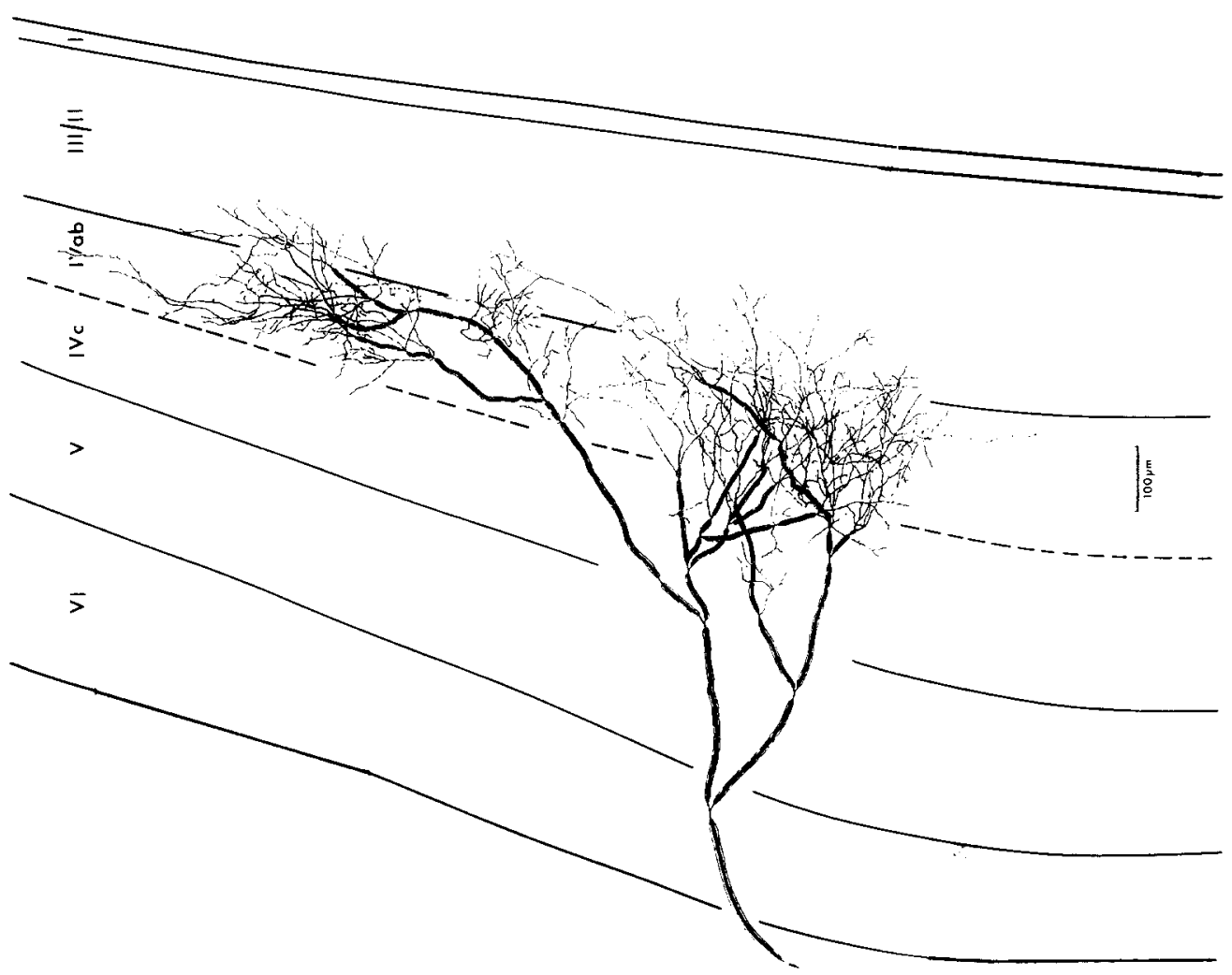

FIG. 18. An axonal trunk of a lateral geniculate neuron showing extensive arborizations in lamina IVab and the lower part of lamina III of the striate cortex in the cat. [Adapted from Ferster and LeVay (30)].

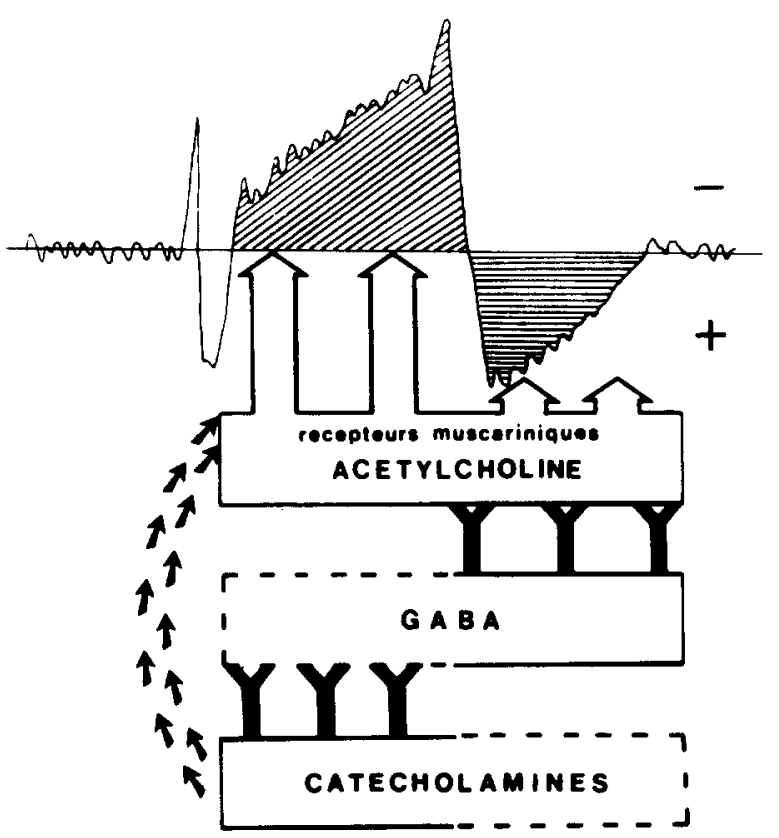

FIG. 19. The "Contingent Negative Variation" (CNV) in the human EEG. In the figure a neurochemical model is presented in which negativity of the CNV is cholinergic regulated, while the postimperative positivity has a GABAergic background. [Adapted from TimsitBerthier (68)].

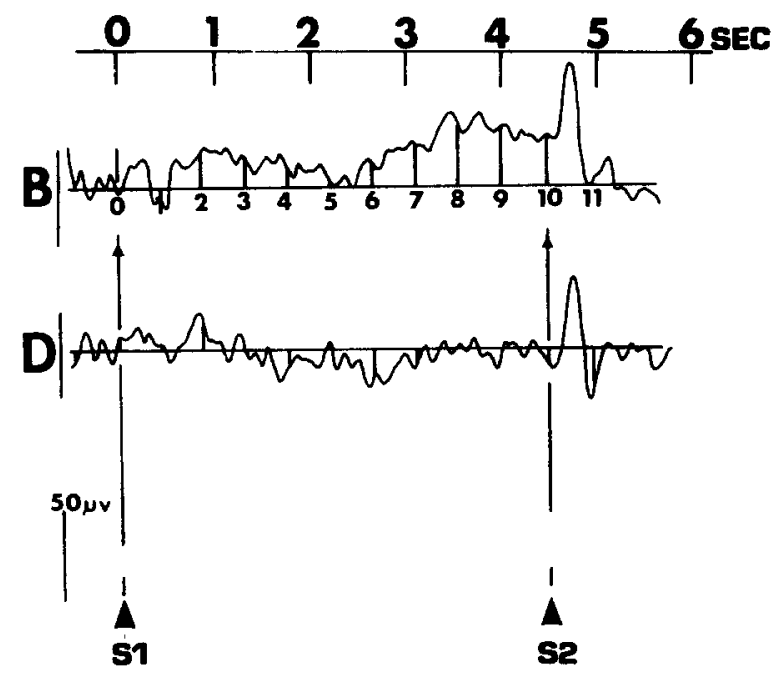

FIG. 20. The human "Contingent Negative Variation" (CNV) determined in a normal state of wakefulness (B) (top trace) and after a prolonged period of sleep deprivation (D) (bottom trace). In the latter trace the negativity does not appear, presumably by a decrease in preparation due to the high sleep propensity. [Adapted from Naitoh et al. (52)]. 


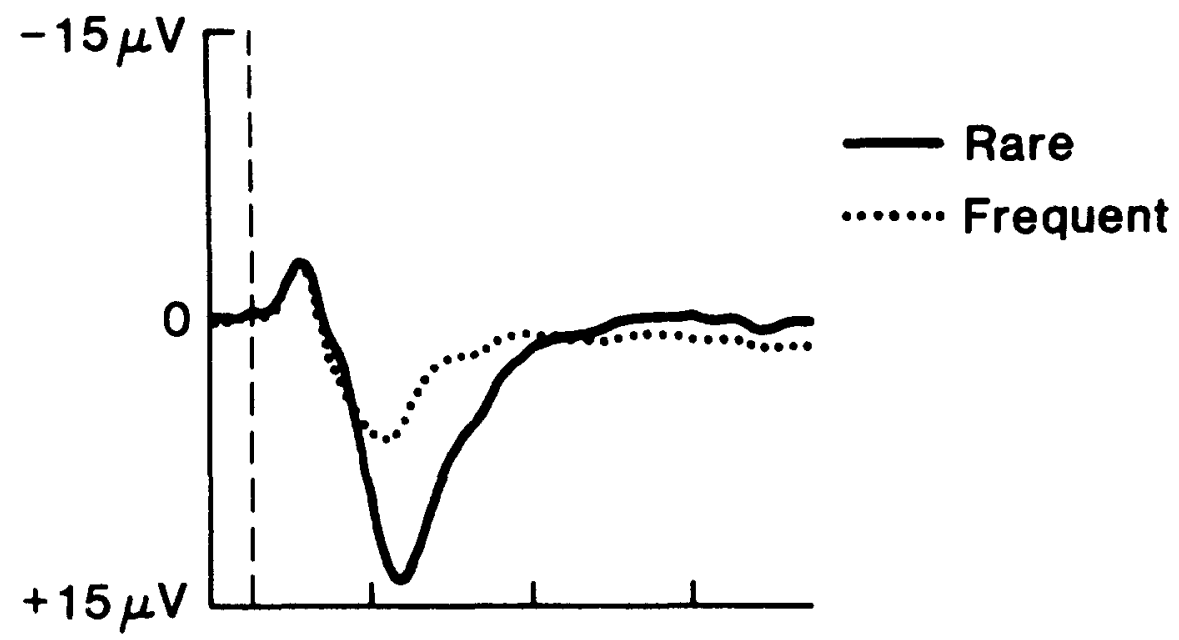

FIG. 21. Grand average of the auditory evoked potential of humans in an "oddball"paradigm. Following an initial negative wave, a prominent P300 becomes visible, especially when a rare stimulus is presented. Stimulus onset is displayed at the broken vertical line and positivity is directed downwards. The time scale indicated on the $x$-axis is 400 msec. [Adapted from Donchin and Fabiani (23)].

quently applied method to elicit a P300 (Fig. 21). In this paradigm a standard stimulus is frequently presented, rarely replaced by an oddball or target, a deviant stimulus for which a reaction is asked. Elicitation of the $P 300$ is contingent on the recognition of the target. The appearance and size of P300 is dependent on processes underlying the recognition of the stimulus (23). It is of interest to note that during sleep, a P300, though smaller in amplitude, can be elicited by a deviant stimulus (56). This means that during sleep a kind of evaluation of incoming information can occur; a conclusion already drawn earlier.

When studying EEG polarity and neuronal activities, one may assume that late ERP components, primarily dependent on the meaning of the stimulus to the subject, are brought about in a manner similar to the early components. A question may be forwarded concerning the possibility that the large positive component P300 in the ERP is the expression of hyperpolarizations of thalamocortical neurons. The P300 wave occurs under a condition needing selective attention to distinguish the target stimulus from the expected (standard) one. Is it possible that inhibitory activities play a role in the process of evaluating or comparing information? Theoretically, the correct information may be more easily accessible by a closure of alternative pathways.
It is generally argued that thalamic originating activities may be measured in a scalp recording of an EEG, near where synaptic potentials in cortical superficial layers are found. Through this cortical organization, excitatory activities are measured as negative directed EEG waves, while inhibitory activities are reflected by positive directed potentials. Furthermore, small high frequency waves are the summed neuronal activity of cells firing in a tonic, asynchronized, way. In this situation, sensory information reaches the cortical areas and information processing takes place. On the other hand, large EEG waves are composed of synchronous, collective neuronal firing in a burst mode. The latter also implies that sensory gates are mostly closed and information processing is at a low level. Nevertheless, there is evidence to assume that what still passes to the cortical areas is enough for a shallow, subconscious, evaluation.

\section{ACKNOWLEDGEMENTS}

The author is indebted to Dr. Gilles van Luijtelaar, Dr. Pim Drinkenburg, Prof. Michael Coles, Prof. George Kostopoulos and Prof. Jo Vossen for their valuable and stimulating suggestions and commentary. All figures used with the permission of the authors.

\section{REFERENCES}

1. Aleksandrov, I.; Maksimova, N. Slow brain potentials and their relation to the structure of behavior: Data on cortical unit activity. In: Johnson, R.; Rohrbauch, J. W.; Parasuraman, R., eds. Current trends in event-related potential research (EEG Suppl. 40). Elsevier Science Publishers; 3-7; 1987.

2. Andersen, P. Andersson, S. A. Physiological basis of the alpha rhythm. New York: Meredith Corporation; 1968.

3. Avoli, M.; Gloor, P.; Kostopoulos, G. Gotman, J. An analysis of penicillin-induced generalized spike and wave discharges using simultaneous recordings of cortical and thalamic neurons. J. Neurophysiol. 50:819-837; 1983 .

4. Beck, A. Die Ströme der Nervencentren. Centralbl. Physiol. 4: $572-573 ; 1890$.

5. Berger, H. Uber das Elektrenkephalogramm des Menschen. Arch. Psychiat. Nervenkr. 87:527-570; 1929.
6. Birbaumer, N.; Elbert, T.; Canavan, A. G. M. Rockstroh, B. Slow potentials of the cerebral cortex and behaviour. Physiol. Rev. 70:1-41; 1990.

7. Bonnet, M. H. Performance during sleep. In: Webb, W. B., ed. Biological rhythms sleep and performance. New York: John Wiley \& Sons; 205-237; 1982.

8. Buzsáki, G. The thalamic clock: Emergent network properties. J. Neurosci. 8:4007-4026; 1991

9. Buzsáki, G.; Bickford, R. G.; Armstrong, D. M.; Ponomareff, G.; Chen, K. S.; Ruiz, R.; Thal, L. J. Gage, F. H. Electrical activity in the neocortex of freely moving young and aged rats. Neurosci. 26:735-744; 1988.

10. Caspers, H.; Speckmann, E. J. Lemenkühler, A. Electrogenesis of cortical DC potentials. In: Kornhuber, H. H.; Deecke, H., eds. Progress in brain research. vol. 54. Amsterdam: Elsevier; 1980:3-16. 
11. Caton, R. The electrical currents of the brain. Br. Med. J. 2:278; 1875.

12. Coenen, A. M. L. Frequency analysis of rat hippocampal electrical activity. Physiol. Behav. 14:391-394; 1975.

13. Coenen, A. M. L. In Morpheus' armen. Assen: van Gorcum; 1985.

14. Coenen, A. M. L. Eijkman, E. G. J. Cat optic tract and geniculate unit responses corresponding to human visual masking effects. Exp. Brain Res. 15:441-451; 1972.

15. Coenen, A. M. L. Vendrik, A. J. H. Determination of the transfer ratio of cat's geniculate neurons through quasi-intracellular recordings and the relation with the level of alertness. Exp. Brain Res. 14:227-242; 1972.

16. Coenen, A. M. L.; Gerrits, H. J. M.; Vendrik, A. J. H. Analysis of the response characteristics of optic tract and geniculate units and their mutual relationship. Exp. Brain Res. 15:452-471; 1972.

17. Coenen, A. M. L.; Drinkenburg, W. H. I. M.; Inoue, M.; van Luijtelaar, E. L. J. M. Genetic models of absence epilepsy, with emphasis on the WAG/Rij strain of rats. Epilepsy Res. 12:75-86; 1992.

18. Creutzfeldt, O.; Watanabe, S.; Lux, H. D. Relations between EEG phenomena and potentials of single cortical cells. II. Spontaneous and convulsoid activity. Electroenceph. Clin. Neurophysiol. 20:19-37; 1966.

19. Curró Dossi, R.; Nuñez, A.; Steriade, M. Electrophysiology of a slow $(0.5-4 \mathrm{~Hz})$ intrinsic oscillation of cat thalamocortical neurones in vivo. J. Physiol. 447:215-234; 1992.

20. Davis, P. A. Effects of acoustic stimuli on the waking human brain. J. Neurophysiol. 2:494-499; 1939.

21. Davis, H.; Davis, P. A.; Loomis, A. L.; Harvey, E. N. Hobart, G. Electrical reactions of the human brain to auditory stimulation during sleep. J. Neurophysiol. 2:500-514; 1939.

22. Dawson, G. D. A summation technique for the detection of small evoked potentials. Electroenceph. Clin. Neurophysiol. 6:65-84; 1954.

23. Donchin, E.; Fabiani, M. The use of event-related brain potentials in thestudy of memory: Is P300 a measure of event distinctiveness? In: Jennings, J. R.; Coles, M. G. H., eds. Handbook of cognitive psychophysiology: Central and autonomic nervous system approaches. New York: John Wiley \& Sons; 471-498; 1991.

24. Donchin, E.; Lindsley, D. B. Average evoked potentials. Methods, results, and evaluations. Washington: National Aeronautics and Space Administration; 1969.

25. Drinkenburg, W. H. I. M.; van Luijtelaar, E. L. J. M.; Coenen, A. M. L. Oscillations are induced in the EEG of rats by sleep deprivation. In: Coenen, A. M. L., ed. Sleep-wake research in the Netherlands. vol. 3. 1992:53-54.

26. Drinkenburg, W. H. I. M.; Coenen, A. M. L.; Vossen, J. M. H.; van Luijtelaar, E. L. J. M. Spike-wave discharges and sleep-wake states in rats with absence epilepsy. Epilepsy Res. 9:218-224; 1991.

27. Drinkenburg, W.; Schuurmans, M.; Coenen, A. van Luijtelaar, E. Information processing during absence epilepsy in rats: Effects of stimulus impact. Neurophysiol. Clin. 22 S1:55; 1992.

28. Drinkenburg, W. H. I. M.; van Luijtelaar, E. L. J. M.; van Schaijk, W. J.; Coenen, A. M. L. Aberrant transients in the EEG of epileptic rats: A spectral analytical approach. Physiol. Behav. 54:779-783; 1993.

29. Elbert, T.; Rockstroh, B. Threshold regulation-A key to the understanding of the combined dynamics of EEG and eventrelated potentials. J. Psychophysiol. 4:317-333.

30. Ferster, D.; LeVay, S.: The axonal arborizations of lateral geniculate neurons in the striate cortex of the cat. J. Comp. Neur. 182: 923-944; 1978.

31. Gilbert, C. D.; Wiesel, T. N. Morphology and intracortical projections of functionally characterised neurones in the cat visual cortex. Nature 280:120-125; 1979.

32. Glenn, L. L.; Steriade, M. Discharge rate and excitability of cortically projecting intralaminar thalamic neurons during waking and sleep states. J. Neurosci. 2:1387-1404; 1982.
33. Glenn, L. L.; Foutz, A. S. Dement, W. C. Membrane potential of spinal motoneurons during natural sleep in cats. Sleep 1:199204; 1978.

34. Gottesmann, C. Le stade intermédiaire du sommeil chez le rat. Rev. Electroencephalogr. 3:65-68; 1972.

35. Gray, C.; Singer, W. Stimulus-specific neuronal oscillations in orientation columns of cat visual cortex. Proc. Natl. Acad. Sci. $86: 1698-1702 ; 1989$.

36. Gray, C.; König, P.; Engel, A. K. Singer, W. Oscillatory responses in cat visual cortex exhibit inter-columnar synchronization which reflects global stimulus properties. Nature 338:334337; 1989.

37. Hall, R. D. Borbély, A. A. Acoustically evoked potentials in the rat during sleep and waking. Exp. Brain Res. 11:93-110; 1970.

38. Hirsch, J. C.; Fourment, A.; Marc, M. E. Sleep-related variations of membrane potential in the lateral geniculate body relay neurons of the cat. Brain Res. 259:308-312; 1983.

39. Inoue, M.; Duysens, J.; Vossen, J. M. H.; Coenen, A. M. L. Thalamic multiple unit activity underlying spike-wave discharges in anesthetized rats. Brain Res. 612:35-40; 1993.

40. Inoue, M.; van Luijtelaar, E. L. J. M.; Vossen, J. M. H.; Coenen, A. M. L. Visual evoked potentials during spontaneously occurring spike-wave discharges in rats. Electroenceph. Clin. Neurophysiol. 84:172-179; 1992.

41. Karmos, G.; Molnár, M.; Cépe, V.; Winkler, I. Grinchenko, $Y$. V. Evoked cortical field potential and unit responses in the wakefulness-sleep cycle in cats. In: Koella, W. P.; Obál, F.; Schulz, H.; Visser, P., eds. Sleep '86. Stuttgart: Gustav Fischer Verlag; 287-289; 1988.

42. Kellaway, P. Sleep and epilepsy. Epilepsia 26 (S1) S15-S30; 1985.

43. Koelega, H. S. Stimulant drugs and vigilance performance: A review. Psychopharmacology 111:1-16; 1993.

44. Kostopoulos, G. Gloor, P.: A mechanism for spike-wave discharge in feline penicillin epilepsy and its relationship to spindle generation. In: Sterman, M. B.; Shouse, M. N.; Passouant, P. Sleep and Epilepsy. Academic Press; 11-27; 1982.

45. Kostopoulos, G.; Gotman, J. Computer assisted analysis of relations between single-unit activity and spontaneous EEG. Electroenceph. Clin. Neurophysiol. 57:69-82; 1984.

46. Kornhuber, H. H.; Deecke, L. Hirnpotentialänderungen bei Willkürbewegungen und passiven Bewegungen des Menschen: Bereitschaftspotential und reafferente Potentiale. Pflügers Archiv 284: $1-17 ; 1965$.

47. Langford, G. W.; Meddis, R.; Pearson, A. J. D. Awakening latency from sleep for meaningful and nonmeaningful stimuli. Psychophysiology 11:1-5; 1974.

48. Livingstone, M. S.; Hubel, D. H. Effects of sleep and arousal on the processing of visual information in the cat. Nature 291:554$561 ; 1981$.

49. Llinás, R.; Ribary, U. Coherent $40-\mathrm{Hz}$ oscillation characterizes dream state in humans. Proc. Natl. Acad. Sci. 90:2078-2081; 1993.

50. Marescaux, C.; Micheletti, G.; Vergnes, M.; Depaulis, A.; Rumbach, L. Warter, J. M. A model of chronic spontaneous petit mal-mal seizures in the rat: Comparison with pentylenetetrazolinduced seizures. Epilepsia 25:326-331; 1984.

51. Mulle, C.; Madariaga, A.; Deschênes, M. Morphology electrophysiological properties of reticularis thalamic neurons in cat: In vivo study of a thalamic pacemaker. J. Neurosci. 6:2134-2145; 1986.

52. Naitoh, P.; Johnson, L. C.; Lubin, A. Modification of surface negative slow potential (CNV) in the human brain after total sleep loss. Electroenceph. Clin. Neurophys. 30:17-22; 1971.

53. Nuñez, A.; Curró Dossi, R.; Contreras, D. Steriade, M. Intracellular evidence for incompatibility between spindle and delta oscillations in thalamocortical neurons of cat. Neuroscience 48:75-85; 1992.

54. Oswald, I.; Taylor, A. M.; Treisman, M. Discriminative responses to stimulation during human sleep. Brain 83:440-453; 1960.

55. Pedley, T. A.; Traub, R. D. Physiological basis of the EEG. In: 
Daly, D. D.; Pedley, T. A. Current practice of clinical electroencephalography. New York: Raven Press; 1990:107-137.

56. Salisbury, D.; Squires, N. K.; Ibel, S. Maloney, T. Auditory event-related potentials during stage 2 NREM sleep in humans. J. Sleep Res. 1:251-257; 1992.

57. Singer, $W$. The effect of mesencephalic reticular stimulation on intracellular potentials of cat lateral geniculate neurons. Brain Res. 61:35-54; 1973.

58. Singer, W. Control of thalamic transmission by corticofugal and ascending reticular pathways in the visual system. Physiol. Rev. $57: 386-420 ; 1977$.

59. Speckmann, E.-J. Elger, C. E. Neurophysiological basis of the EEG and of DC potentials. In: Niedermeyer, E.; Lopes da Silva, F., eds. Electroencephalography. Basic principles, clinical applications and related fields. Urban \& Schwarzenberg; 1982: 1-13.

60. Steriade, M. Alertness, quiet sleep, dreaming. In: Peters, A., ed. Cerebral cortex, vol. 9. New York: Plenum Press: 1991:279-357.

61. Steriade, M.; Buzsáki, G. Parallel activation of thalamic and cortical neurons by brainstem and basal forebrain cholinergic systems. In: Steriade, M.; Biesold, D. Brain cholinergic systems. Oxford: Oxford Medical Press; 1990:3-64.

62. Steriade, M.; McCarley, R. W. Brainstem control of wakefulness and sleep. New York: Plenum Press; 1990.

63. Steriade, M.; Gloor, P.; Llinás, R. R.; Lopes da Silva, F. H. Mesulam, M.-M. Basic mechanisms of cerebral rhythmic activities. Electroenceph. Clin. Neurophysiol. 76:481-508; 1990.

64. Steriade, M.; Jones, E. G.; Llinás, R. R. Thalamic oscillations and signalling. New York: John Wiley \& Sons; 1990.

65. Steriade, M.; McCormick, D. A.; Sejnowski, T. J. Thalamocortical oscillations in the sleeping and aroused brain. Science 262: $697-685 ; 1993$.
66. Sutton, S.; Braren, M.; Zubin, J.; John, E. R. Evoked potential correlates of stimulus uncertainty. Science 150:1187-1188; 1965.

67. Thompson, J. W.; Ashton, H.; Golding, J. F. Marsh, V. R. Pharmacology of event-related potentials in humans. In: McCallum, W.; Zappoli, R.; Denoth, F., eds. Cerebral psychophysiology: Studies in event-releted potentials. Elsevier Science Publishers; EEG 1986:(Suppl. 38):374-392.

68. Timsit-Berthier, M. A propos de l'interprétation de la variation contingente négative en psychiatrie. Rev. E. E. G. Neurophysiol. 11:236-244; 1981

69. Vanderwolf, C. H. Neocortical and hippocampal activation in relation to behavior: Effects of atropine, eserine, phenothiazines and amphetamine. J. Comp. Physiol. Psychol. 88:300-322; 1975.

70. Van Hulzen, Z. J. M.; Coenen, A. M. L. Photically evoked potentials in the visual cortex following paradoxical sleep deprivation in rats. Physiol. Behav. 32:557-563; 1984.

71. Van Luijtelaar, E. L. J. M.; Coenen, A. M. L. Two types of electrocortical paroxysms in an inbred strain of rats. Neurosci. Lett. 70:393-397; 1986.

72. Van Luijtelaar, E.; Coenen, A. The behavioral pharmacology of sleep. In: Van Haaren, F., ed. Methods in behavioral pharmacology. Elsevier Science Publishers; 1993:575-602.

73. Vaughan, H. G. The relationship of brain activity to scalp recordings of event-releted potentials. In: Donchin, E.; Lindsley, D. B. eds. Average evoked potentials. Methods, results, and evaluations. Washington: National Aeronautics and Space Administration. 45-94; 1969.

74. Walter, W. G. Slow potential waves in the human brain associated with expectancy, attention and decision. Arch. Psychiat. Nervenkr. 206:309-322; 1964.

75. Zung, W. W. K.; Wilson, W. P. Response to auditory stimulation during sleep. Arch. Gen. Psychiatry 4:548-552; 1961. 